NBER WORKING PAPER SERIES

\title{
DYNAMIC STRATEGIC CORPORATE FINANCE: A TUG OF WAR WITH FINANCIAL FRICTIONS
}

\author{
Ulrich Doraszelski \\ João F. Gomes \\ Felix Nockher \\ Working Paper 29310 \\ http://www.nber.org/papers/w29310 \\ NATIONAL BUREAU OF ECONOMIC RESEARCH \\ 1050 Massachusetts Avenue \\ Cambridge, MA 02138 \\ September 2021
}

We are grateful to Mike Abito and Juuso Toikka for many helpful discussions and to Rich Kihlstrom and Vojislav Maksimovic for detailed comments on earlier drafts, as well as seminar participants at Guanghua, Microsoft, Ohio State, Wharton, and the World Congress of the Econometric Society. Douglas King and Hugh MacMullan provided invaluable help with setting up computing environments for us on Wharton's HPC Cluster and AWS. Ralf Giering helped us use TAF. Alexander Belyakov and Mehran Ebrahimian provided excellent research assistance. Doraszelski and Gomes gratefully acknowledge financial support from The Wharton School's Dean's Research Fund and the National Science Foundation under award number 2117068. The views expressed herein are those of the authors and do not necessarily reflect the views of the National Bureau of Economic Research.

NBER working papers are circulated for discussion and comment purposes. They have not been peer-reviewed or been subject to the review by the NBER Board of Directors that accompanies official NBER publications.

(C) 2021 by Ulrich Doraszelski, João F. Gomes, and Felix Nockher. All rights reserved. Short sections of text, not to exceed two paragraphs, may be quoted without explicit permission provided that full credit, including $(\mathcal{O}$ notice, is given to the source. 
Dynamic Strategic Corporate Finance: A Tug of War with Financial Frictions

Ulrich Doraszelski, João F. Gomes, and Felix Nockher

NBER Working Paper No. 29310

September 2021

JEL No. G3,L1

\begin{abstract}
$\underline{\text { ABSTRACT }}$
Access to capital markets plays a key role for the evolution of an industry over time. We develop a benchmark theoretical setting that integrates core corporate finance insights about the impact of financial frictions on investment with those from industrial organization on dynamic competition and industry evolution under perfect capital markets. Using state of the art computational tools to systematically detect and evaluate multiple equilibria and to thoroughly explore the parameter space of our model, we show how, depending on key industry characteristics such as market size, financial frictions impact firms' pricing and investment strategies and the degree of industry concentration.

Ulrich Doraszelski

The Wharton School

University of Pennsylvania

3733 Spruce Street,

Philadelphia, PA 19104

and NBER

doraszelski@wharton.upenn.edu

João F. Gomes

The Wharton School

University of Pennsylvania

3620 Locust Walk

Philadelphia, PA 19104

gomesj@wharton.upenn.edu

Felix Nockher

The Wharton School

University of Pennsylvania

3620 Locust Walk

Philadelphia, PA 19104

fnockher@wharton.upenn.edu
\end{abstract}

A data appendix is available at http://www.nber.org/data-appendix/w29310 


\section{Introduction}

Since at least the development of canals and railroads, at the very beginning of the modern era, nascent industries often experience a turbulent start, as firms invest heavily and compete fiercely to acquire a dominant position. During these intensely competitive phases, capital is critical and access to financing can meaningfully affect a firm's ability to succeed. The ongoing battle for market dominance in the online food delivery industry, where the large potential market size has led firms to rapidly expand their networks of restaurants and use aggressive price discounts to win diners, is but one dramatic contemporary example of the importance of access to capital markets, with key players like Uber Eats, DoorDash and others requiring regular capital injections to remain competitive.

In this paper, we seek to understand how limitations in the access to capital markets impact the dynamic strategic interactions between firms and the evolution of an industry over time. To do this, we must bridge the gap between the industrial organization literature that assumes perfect capital markets, where every NPV-positive investment project can be funded in a costless way, and the corporate finance literature that hones in on financial frictions but takes industry dynamics as exogenous and almost always assumes away strategic interactions between firms.

We develop and analyze a benchmark theoretical setting that integrates core corporate finance insights about the impact of financial frictions on investment in models without strategic interactions with those of the literature following Ericson \& Pakes (1995) on industry dynamics without financial frictions. The basic setting combines the Budd, Harris \& Vickers (1993) model of dynamic competition and industry evolution with a model of investment under financial frictions à la Gomes (2001). Although our model is designed for tractability rather than detailed realism, a thorough analysis proves immensely complex and requires state of the art computational tools. In particular, our model inherits the possibility of multiple equilibria from Budd et al. (1993) but, whereas they study only a few examples, we aim to systematically detect and evaluate multiple equilibria.

Our findings indicate that linking the industrial organization and corporate finance literatures is a very promising undertaking. In particular, we show that accounting for strategic interactions can be of first-order importance for our understanding of the impact of financial frictions on both price and investment. Moreover, we show that financial frictions are often consequential for the evolution of an industry over time. By thoroughly exploring the parameter space of our model, we show that, depending on key industry characteristics such as market size, the degree of product differentiation, and the level of possible regulatory intervention, financial frictions may lead firms to charge lower or higher prices and to invest more or less. Financial frictions may also cause an industry to become more or less concentrated over time. Our insights on how financial frictions affect prices and competitiveness are particularly relevant for policymakers in light of the recent discussion about the rise of market power and its 
possible origins (e.g., Berry, Gaynor \& Scott-Morton 2020).

Probably our most surprising finding is the realization that in several cases the dynamic strategic interactions between firms actually lead firms to invest more in the presence of financial frictions. This finding is at odds with almost all extant work in corporate finance. In effect, accounting for strategic interactions challenges the null hypothesis that financially constrained firms invest less in virtually every empirical study seeking to document the pervasiveness of financial frictions in the data.

Finally, we show that financial frictions can also impact the degree of industry concentration, both in the long run and along the transition path. While financial frictions tend to lead to more asymmetric industry structures and to accelerate convergence towards these structures, we also document several cases where the opposite happens.

Beyond these and other significant quantitative effects, financial frictions add an important qualitative feature: prices can no longer be treated as static decisions and instead must be understood and analyzed jointly with firms' other dynamic decisions such as investment, advertising, and R\&D. This is because prices and profits directly impact the extent to which costly external financing is required to fund investments and, thus, how the industry evolves over time. As a result, the "traditional staticdynamic breakdown" (Doraszelski \& Pakes 2007, p. 1892) that underlies much of empirical and theoretical research in industrial organization no longer holds.

Related literature. Many papers study the impact of financial frictions in the context of models of industry dynamics à la Hopenhayn (1992).1 In these models, there is a continuum of firms. Because none of their actions has an impact on their rivals, there is no room for strategic interactions between firms.

Oligopolistic industries have been introduced in recent structural banking models (e.g., Corbae \& D'Erasmo (2021) and Wang, Whited, Wu \& Xiao (2021)), where financing and regulation play an important role in banks' decisions. These papers are largely concerned with macro aggregates and hold the degree of industry concentration exogenous, while we endogenize the evolution of the industry and its degree of concentration. Treating industry concentration as exogenous is also common in the macro literature that studies the impact of financial frictions on variables such as aggregate output, aggregate investment, and the labor share in the presence of market power (e.g., Midrigan \& Xu 2014).

The focus of our paper is closer to an older literature that studies the impact of (exogenous) debt and limited liability on product market competition either in static models (Brander \& Lewis 1986) or in repeated games (Maksimovic 1988). Strategic interactions are similarly at the forefront of some models of predatory pricing (Telser 1966, Bolton \& Sharfstein 1990). Another important early paper is Fershtman \& Judd (1987), who study how differences between owners and managers impact product

\footnotetext{
${ }^{1}$ Some early examples are Cooley \& Quadrini (2001), Gomes (2001), Albuquerque \& Hopenhayn (2004), and Clementi \& Hopenhayn (2006).
} 
market competition. Although we do not explicitly model the divergent interests of owners and managers in our paper, we recognize that financial frictions ultimately arise precisely because of them.

Also close to us are the recent papers by Dou, Ji \& Wu (2021) and Liu, Mian \& Sufi (2021). Both develop dynamic strategic competition settings to suggest that a low discount rate due to either low risk premia or loose monetary policy mitigates product market competition and exacerbates industry concentration. However, neither paper allows for financial frictions, which effectively decouples changes in the discount rate (with or without risk premia) required by households or investors from the effective cost of external funds to firms making pricing and investment decisions.

Finally, our paper is related to the vibrant literature studying the effect of the purported rise in industry concentration on aggregate investment and the rates of innovation and business dynamism (e.g., Akcigit \& Ates 2020). This literature also abstracts from financial frictions.

Paper structure. The rest of the paper is organized as follows. Section 2 develops the model. Section 3 describes our computational approach and some of the main properties of the equilibria. Section 4 discusses the impact of financial frictions on price, investment, and industry concentration. Section 5 concludes. In the Online appendix, we briefly summarize recent developments in the online food delivery industry and the importance of access to financing. We also provide additional results that supplement the main text.

\section{Model}

Our model captures the impact of financial frictions on the dynamics of an industry and its long-run competitiveness. Absent financial frictions, our model is similar to Budd et al. (1993). While stylized, their model has the advantage that the industry dynamics it generates are well understood. As such, it is a natural starting point for studying the impact of financial frictions.

We consider a discrete-time, infinite-horizon dynamic stochastic game between two forward-looking firms that compete for a dominant position through their pricing and investment decisions. At any point in time, the state variable $\omega \in\{-L,-L+1, \ldots, L\}$ summarizes the state of competition in the industry. If $\omega>0$, firm 1 is the leader and firm 2 is the follower; if $\omega<0$, firm 1 is the follower and firm 2 is the leader; and if $\omega=0$, the firms compete head-to-head. The size of the competitive advantage that the leader enjoys over the follower is defined as $|\omega|$.

By investing, a firm aims to increase its competitive advantage (or decrease its competitive disadvantage), capture market share, and eventually generate profit. The law of motion for the state is

$$
\omega^{\prime}=\max \left\{-L, \min \left\{L, \omega+x_{1}-x_{2}\right\}\right\},
$$


where $x_{i} \in\{0,1\}$ is the investment decision of firm $i \in\{1,2\}$ and we use a prime to distinguish subsequent-period from current-period values. As in a tug of war, investing thus allows a firm to move the state to "its" side.

The state $\omega$ can capture many potential sources of competitive advantage such as branding, network effects, or learning economies, and investing can accordingly entail spending on marketing or R\&D. For concreteness, we think of the firms as offering products that differ in how consumers perceive their qualities. In this scenario, the state $\omega$ captures the difference in product qualities. By investing, a firm aims to increase the quality of its product relative to that of its competitor.

Because of financial frictions firm $i$ 's cost of investing decreases in its profit, as we discuss below in detail. Financial frictions therefore link the pricing and investment decisions. We assume that in each period the firms make these decisions in two stages: they first decide on prices and then on investments.

We begin by detailing the product market and other primitives of the model before moving on to firms' decisions in the pricing and investment stages.

Product market. The products offered by the firms are differentiated vertically (as captured by the state $\omega$ ) and horizontally. ${ }^{2}$ The demand for product 1 is given by the logistic function

$$
M \frac{1}{1+\exp \left(\frac{-g(\omega)+\alpha\left(p_{1}-p_{2}\right)}{\nu}\right)},
$$

where $p_{i}$ is the price charged by firm $i, M>0$ is market size, $\alpha>0$ price sensitivity, and $\nu>0$ the degree of horizontal product differentiation. As $\nu$ increases, the products become more differentiated, thus softening price competition between the firms. The demand for product 2 is analogously

$$
M \frac{1}{1+\exp \left(\frac{-g(-\omega)-\alpha\left(p_{1}-p_{2}\right)}{\nu}\right)} .
$$

The function $g(\omega)$ maps the state of competition into consumers' quality perceptions and demand. We parameterize

$$
g(\omega)=\left\{\begin{array}{clc}
\frac{\omega}{L} & \text { if } \quad \omega<0 \\
\tau \frac{\omega}{L} & \text { if } & \omega \geq 0
\end{array}\right.
$$

where $\tau \in[0,1]$ is a handicap parameter. Note that $g(-L)=-1, g(0)=0$, and $g(L)=\tau$. A smaller value of $\tau$ therefore imposes a disadvantage on the leader. In the extreme of $\tau=0, g(\omega)=0$ for all $\omega \geq 0$ and the size of the competitive advantage

\footnotetext{
${ }^{2}$ Budd et al. (1993) discuss a number of alternative models of product market competition that fit into our setup.
} 
that the leader enjoys over the follower is irrelevant for how consumers perceive the leader's product. More generally, a smaller value of $\tau$ can also reflect the impact of regulation or antitrust policy measures that impose a greater burden on the leader.

The per-period profit of firm 1 is

$$
\pi_{1}\left(\omega, p_{1}, p_{2}\right)=M \frac{1}{1+\exp \left(\frac{-g(\omega)+\alpha\left(p_{1}-p_{2}\right)}{\nu}\right)}\left(p_{1}-c\right),
$$

where $c \geq 0$ is the marginal cost of production. The profit of firm 2 is symmetric to that of firm 1:

$$
\pi_{2}\left(\omega, p_{1}, p_{2}\right)=\pi_{1}\left(-\omega, p_{2}, p_{1}\right) .
$$

Examination of the static Nash equilibrium in Appendix A shows that we can normalize $\alpha=1$ and $c=0$ without loss of generality. Hence, in what follows we restrict attention to the remaining three key demand parameters: market size $M$, degree of horizontal product differentiation $\nu$, and leader handicap $\tau$.

Investment and financing. To simplify the exposition, we focus on the problem of firm 1 from hereon. The expressions for firm 2 are analogous.

Firm 1 has the opportunity to expand its competitive advantage in each period by investing and incurring a cost $F_{0}>0$. Crucially, capital markets are not frictionless in our model. If its profit $\pi_{1}=\pi_{1}\left(\omega, p_{1}, p_{2}\right)$ is not sufficiently large to cover its investment outlays $F_{0} x_{1}$, then the firm must tap capital markets and raise external funds in the amount of $F_{0} x_{1}-\pi_{1}$. This, in turn, entails an additional cost. As a result, the budget constraint of firm 1 is

$$
d_{1}=\left\{\begin{array}{ccc}
\pi_{1}-F_{0} x_{1} & \text { if } & \pi_{1}-F_{0} x_{1} \geq 0, \\
(1+\lambda)\left(\pi_{1}-F_{0} x_{1}\right) & \text { if } & \pi_{1}-F_{0} x_{1}<0,
\end{array}\right.
$$

where $d_{1}$ is the net distribution to the investors of firm 1 and $\lambda \geq 0$ the per-dollar cost of raising external funds.

Following Gomes (2001), we allow the per-dollar cost of raising external funds to increase in the amount raised and parameterize

$$
\lambda=\zeta\left(F_{0} x_{1}-\pi_{1}\right)^{\kappa-1},
$$

where $\zeta \geq 0$ governs the severity of the financial frictions and $\kappa \in \mathbb{N}$ is a smoothness parameter. The budget constraint in equation (6) can then be written more compactly as

$$
d_{1}=\pi_{1}-F_{0} x_{1}-\zeta \max \left\{0, F_{0} x_{1}-\pi_{1}\right\}^{\kappa} .
$$

The effective cost to firm 1 of investing $\left(x_{1}=1\right)$ is therefore

$$
F\left(\pi_{1}\right)=F_{0}+\zeta \max \left\{0, F_{0}-\pi_{1}\right\}^{\kappa}
$$


and that of not investing $\left(x_{1}=0\right)$ is zero as long as $\pi_{1} \geq 0$.

Following Doraszelski \& Satterthwaite (2010), instead of considering mixed strategies, we add a privately observed random component $\theta_{1}$ to the cost of investing $F\left(\pi_{1}\right)$. We assume that $\theta_{1}$ is drawn anew each period. A high realization of the cost shock $\theta_{1}$ means that the firm's current investment opportunity is poor. We assume that firm 1 observes $\theta_{1}$ only after it made its pricing decision ${ }^{3}$ We further assume that $\theta_{1} \sim N\left(0, \sigma^{2}\right)$ and use $\psi\left(\theta_{1}\right)$ and $\Psi\left(\theta_{1}\right)$ to denote its density and cumulative distribution functions, respectively. The parameter $\sigma>0$ controls cost volatility.

Without loss of generality, we normalize $F_{0}=1$ in what follows. This corresponds to making an appropriate choice of monetary units. We set $\kappa=3$ to ensure that $F\left(\pi_{1}\right)$ is twice continuously differentiable. This leaves the severity of the financial frictions $\zeta$ and the cost volatility $\sigma$ as the two key cost parameters. In the special case of $\zeta=0$, financial frictions are absent from our model, as in Budd et al. (1993) and the industrial organization literature more generally. Financial frictions are present in our model as long as $\zeta>0$, and in our numerical analysis we contrast the case of $\zeta=1$ with the case of $\zeta=0$.

\subsection{Optimal strategies}

Given the state $\omega$, the firms in each period first decide on prices $p_{i}(\omega)$ and then on investments $x_{i}(\omega)$. We let $V_{i}(\omega)$ be the beginning-of-period value function of firm $i$ that is determined in the pricing stage and $U_{i}(\omega)$ be the middle-of-period value function that is determined in the investment stage.

Investment stage. Overloading notation, let $U_{1}\left(\omega, \theta_{1}\right)$ denote the value function of firm 1 after it has observed $\theta_{1}$. In contrast, $U_{1}(\omega)$ is defined from an ex-ante perspective and denotes the value function of firm 1 before it has observed $\theta_{1}$. Similarly, $x_{1}\left(\omega, \theta_{1}\right)=x_{1} \in\{0,1\}$ denotes the investment decision of firm 1 after it has observed $\theta_{1}$ and $x_{1}(\omega) \in[0,1]$ the probability that firm 1 invests before it has observed $\theta_{1}$.

The middle-of-period Bellman equation of firm 1 is

$$
\begin{gathered}
U_{1}\left(\omega, \theta_{1}\right)=\max \left\{-F\left(\pi_{1}\right)-\theta_{1}+\beta\left[V_{1}\left(\omega^{+}\right)\left(1-x_{2}(\omega)\right)+V_{1}(\omega) x_{2}(\omega)\right],\right. \\
\left.\beta\left[V_{1}(\omega)\left(1-x_{2}(\omega)\right)+V_{1}\left(\omega^{-}\right) x_{2}(\omega)\right]\right\},
\end{gathered}
$$

where $\beta \in[0,1)$ is the discount factor, $x_{2}(\omega)$ is the probability that firm 2 invests in state $\omega$ as seen from the perspective of firm 1 , and $\omega^{+}=\min \{L, \omega+1\}$ and $\omega^{-}=\max \{-L, \omega-1\}$ are possible successor states to state $\omega$.

The optimal investment decision $x_{1}\left(\omega, \theta_{1}\right)$ is characterized by a simple cutoff rule, where $x_{1}\left(\omega, \theta_{1}\right)=1$ if

$$
F\left(\pi_{1}\right)+\theta_{1} \leq \beta\left[\left(V_{1}\left(\omega^{+}\right)-V_{1}(\omega)\right)\left(1-x_{2}(\omega)\right)+\left(V_{1}(\omega)-V_{1}\left(\omega^{-}\right)\right) x_{2}(\omega)\right]
$$

\footnotetext{
${ }^{3}$ Because $\theta_{i}$ is privately observed by firm $i$, firm 1 does not observe $\theta_{2}$.
} 
and $x_{1}\left(\omega, \theta_{1}\right)=0$ otherwise. The right-hand side is effectively firm 1's marginal $q$ (as in Hayashi 1982). The implied probability that firm 1 invests in state $\omega$ is

$$
x_{1}(\omega)=\Psi\left(-F\left(\pi_{1}\right)+\beta\left[\left(V_{1}\left(\omega^{+}\right)-V_{1}(\omega)\right)\left(1-x_{2}(\omega)\right)+\left(V_{1}(\omega)-V_{1}\left(\omega^{-}\right)\right) x_{2}(\omega)\right]\right) .
$$

Equation (8) captures the layered effects of financial frictions on investment. As usual, the direct impact is to increase the cost of investing $F\left(\pi_{1}\right)$, thus decreasing the investment probability $x_{1}(\omega)$. In addition, as Gomes (2001) points out, increasing $F\left(\pi_{1}\right)$ has an indirect impact by changing the value function $V_{1}(\omega)$. The key novelty in our model is that the strategic interactions between the firms create an additional mechanism for the transmission of financial frictions on investment: firm 1 must now account for the impact of financial frictions on firm 2's investment probability $x_{2}(\omega)$, and vice versa.

Substituting the optimal investment decision $x_{1}\left(\omega, \theta_{1}\right)$ into the Bellman equation (7) and integrating both sides with respect to $\theta_{1}$ yields

$$
\begin{gathered}
U_{1}(\omega)=-F\left(\pi_{1}\right) x_{1}(\omega)-\int_{-\infty}^{\Psi^{-1}\left(x_{1}(\omega)\right)} \theta_{1} d \Psi\left(\theta_{1}\right)+\beta\left[V_{1}\left(\omega^{+}\right) x_{1}(\omega)\left(1-x_{2}(\omega)\right)\right. \\
\left.+V_{1}(\omega)\left(1-x_{1}(\omega)-x_{2}(\omega)+2 x_{1}(\omega) x_{2}(\omega)\right)+V_{1}\left(\omega^{-}\right)\left(1-x_{1}(\omega)\right) x_{2}(\omega)\right] .
\end{gathered}
$$

Appendix B provides an expression for $\int_{-\infty}^{\Psi^{-1}\left(x_{1}(\omega)\right)} \theta_{1} d \Psi\left(\theta_{1}\right)$.

Using Leibniz's rule we can show that

$$
\frac{\partial^{2} U_{1}(\omega)}{\partial x_{1}^{2}}=-\frac{1}{\psi\left(\Psi^{-1}\left(x_{1}(\omega)\right)\right)}<0,
$$

so that equation (8) is necessary and sufficient for a maximum for firm 1. Nevertheless, there may be multiple solutions to the system of equations given by equation (8) and its analogue for firm 2.

Pricing stage. The beginning-of-period Bellman equation of firm 1 is

$$
V_{1}(\omega)=\max _{p_{1}} \pi_{1}\left(\omega, p_{1}, p_{2}(\omega)\right)+U_{1}(\omega)
$$

where $p_{2}(\omega)$ is the price that firm 2 charges in state $\omega$ and $U_{1}(\omega)$ is given in equation (9). Recognizing the dependence of $x_{1}(\omega)$ and $x_{2}(\omega)$ on $\pi_{1}\left(\omega, p_{1}, p_{2}(\omega)\right)$ and $\pi_{2}\left(\omega, p_{1}, p_{2}(\omega)\right)$, the optimal pricing decision $p_{1}(\omega)$ is characterized by

$$
\begin{gathered}
\frac{\partial \pi_{1}\left(\omega, p_{1}(\omega), p_{2}(\omega)\right)}{\partial p_{1}}\left(1-F^{\prime}\left(\pi_{1}\left(\omega, p_{1}(\omega), p_{2}(\omega)\right)\right) x_{1}(\omega)+\frac{\partial U_{1}(\omega)}{\partial x_{2}} \frac{\partial x_{2}(\omega)}{\partial \pi_{1}}\right) \\
+\frac{\partial \pi_{2}\left(\omega, p_{1}(\omega), p_{2}(\omega)\right)}{\partial p_{1}} \frac{\partial U_{1}(\omega)}{\partial x_{2}} \frac{\partial x_{2}(\omega)}{\partial \pi_{2}}=0,
\end{gathered}
$$


where we have used the fact that $\frac{\partial U_{1}(\omega)}{\partial x_{1}}=0$ from the envelope theorem. Appendix C provides expressions for the first-order comparative statics $\frac{\partial x_{i}(\omega)}{\partial \pi_{j}}$. Our use of these comparative statics is akin to the first-order approach in principal-agent models (Rogerson 1985) and avoids introducing prices or profits as additional state variables in the investment stage.

Absent financial frictions $(\zeta=0), F\left(\pi_{1}(\cdot)\right)=F_{0}$ is constant. Thus, $F^{\prime}\left(\pi_{1}(\cdot)\right)=0$ and $\frac{\partial x_{2}(\omega)}{\partial \pi_{j}}=0$ so that equation 11 reduces to the first-order condition $\frac{\partial \pi_{1}\left(\omega, p_{1}(\omega), p_{2}(\omega)\right)}{\partial p_{1}}=0$ for a static Nash equilibrium (see Appendix A). As a consequence, pricing decisions can be decoupled from investment decisions.

This "traditional static-dynamic breakdown" (Doraszelski \& Pakes 2007, p. 1892) that underlies much of empirical and theoretical research in industrial organization no longer holds in the presence of financial frictions $(\zeta>0)$. Equation (11) shows that firm 1 deviates from static Nash pricing to the extent that this allows it to influence firm 2's investment probability $x_{2}(\omega)$, either through influencing $\pi_{1}(\cdot)$ (and thus $x_{2}(\omega)$ via $\frac{\partial x_{2}(\omega)}{\partial \pi_{1}}$ ) or through influencing $\pi_{2}(\cdot)$ (via $\frac{\partial x_{2}(\omega)}{\partial \pi_{2}}$ ). Importantly, pricing and investment decisions are linked because of strategic interactions: in a single-firm model or in a model with a continuum of firms without strategic interactions, the firm would always charge the static monopoly price.

Finally, if $\zeta>0$, then equation (11) is not sufficient for a maximum for firm 1 . As in the investment stage, there may now be multiple solutions to the system of equations given by equation (11) and its analogue for firm 2 .

\subsection{Markov perfect equilibrium}

A Markov perfect equilibrium is a solution to the system of equations consisting of the Bellman equations and optimality conditions for firm 1 in equations (8), (9), (10), and (11), and their analogues for firm 2 for all $\omega \in\{-L, \ldots, L\}$. We focus on symmetric equilibria in which the value and policy functions of firm 2 are related to those of firm 1 by

$$
V_{2}(\omega)=V_{1}(-\omega), \quad U_{2}(\omega)=U_{1}(-\omega), \quad p_{2}(\omega)=p_{1}(-\omega), \quad x_{2}(\omega)=x_{1}(-\omega) .
$$

In a symmetric equilibrium, it suffices to compute the value and policy functions of firm 1. We detail the resulting system of equations in Appendix D.

Because equation (11) is necessary but not sufficient, a solution to this system of equations is not necessarily an equilibrium. We thus check that there is no profitable unilateral deviation from a solution, as detailed in Appendix E.

Industry dynamics. In equilibrium, the law of motion in equation (1) can be written as

$$
\omega^{\prime}=\left\{\begin{array}{ccc}
\omega^{-} & \text {with prob. } & \left(1-x_{1}(\omega)\right) x_{2}(\omega), \\
\omega & \text { with prob. } & 1-x_{1}(\omega)-x_{2}(\omega)+2 x_{1}(\omega) x_{2}(\omega), \\
\omega^{+} & \text {with prob. } & x_{1}(\omega)\left(1-x_{2}(\omega)\right) .
\end{array}\right.
$$


It follows that the expected change in the state $\omega$ is

$$
\Delta(\omega)=E\left[\omega^{\prime} \mid \omega\right]-\omega=\left\{\begin{array}{ccc}
x_{1}(\omega)\left(1-x_{2}(\omega)\right) & \text { if } & \omega=-L, \\
x_{1}(\omega)-x_{2}(\omega) & \text { if } & -L<\omega<L \\
-\left(1-x_{1}(\omega)\right) x_{2}(\omega) & \text { if } & \omega=L .
\end{array}\right.
$$

Hence, away from the boundaries, the dynamics of the state are linear in the difference $x_{1}(\omega)-x_{2}(\omega)$ : the state is expected to increase if firm 1 is more likely to invest than firm 2 and to decrease if firm 1 is less likely to invest than firm 2.4 The difference in the investment probabilities of the leader and the follower is therefore crucial for the dynamics of the industry and its long-run competitiveness.

Equation $(12)$ formally defines the $(2 L+1) \times(2 L+1)$ state-to-state transition probability matrix $P$ of a Markov chain and, as detailed in Appendix F, we compute its $1 \times(2 L+1)$ limiting distribution $\mu^{\infty}$. In what follows, we summarize the implications of equilibrium behavior for the structure of the industry in the long run using the most likely state of the limiting distribution ${ }^{5}$

$$
\widehat{\omega}^{\infty}=\arg \max _{\omega \in\{0, \ldots, L\}} \mu^{\infty}(\omega)
$$

and the expected size of the competitive advantage

$$
\bar{\omega}^{\infty}=\sum_{\omega=-L}^{L}|\omega| \mu^{\infty}(\omega) .
$$

\section{Computation and equilibria}

In this section, we describe our approach to numerically solving the model and the equilibrium behavior that it generates.

\subsection{Parameterization}

Table 1 summarizes the parameters and their ranges. We study our baseline model with financial frictions and contrast it to the special case of $\zeta=0$ without financial frictions. We focus on the four key demand and cost parameters $M, \nu, \tau$, and $\sigma$. We proceed by specifying grids for these parameters while holding the remaining parameters fixed. We then thoroughly explore this parameter space in our numerical analysis.

\footnotetext{
${ }^{4}$ The state is expected to increase at the lower boundary $\omega=-L$ and to decrease at the upper boundary $\omega=L$. The boundaries are repulsive in the terminology of Budd et al. (1993) although the degree of repulsion is endogenous in our model.

${ }^{5}$ In a symmetric equilibrium, restricting attention to $\omega \in\{0, \ldots, L\}$ instead of $\omega \in\{-L, \ldots, L\}$ is without loss of generality.
} 


\begin{tabular}{|c|c|c|c|}
\hline & parameter & range & value/grid \\
\hline state space: & & & \\
\hline $\begin{array}{l}\text { maximum value of } \omega \\
\text { discounting: }\end{array}$ & $L$ & $\mathbb{N}$ & 15 \\
\hline $\begin{array}{l}\text { discount factor } \\
\text { product market. }\end{array}$ & $\beta$ & {$[0,1)$} & 0.95 \\
\hline market size & $M$ & $(0, \infty)$ & $10^{-2}, 10^{-1.9}, 10^{-1.8}, \ldots, 10^{1.9}, 10^{2}$ \\
\hline price sensitivity & $\alpha$ & $(0, \infty)$ & 1 (normalization) \\
\hline degree of horizontal product & & & \\
\hline differentiation & $\nu$ & $(0, \infty)$ & $0.025,0.075,0.125, \ldots, 1.925,1.975$ \\
\hline leader handicap & $\tau$ & {$[0,1]$} & $0,0.05,0.1, \ldots, 0.95,1$ \\
\hline marginal cost & $c$ & {$[0, \infty)$} & 0 (normalization) \\
\hline investment: & & & \\
\hline fixed cost & $F_{0}$ & $(0, \infty)$ & 1 (normalization) \\
\hline severity of financial frictions & $\zeta$ & {$[0, \infty)$} & 0,1 \\
\hline smoothness of financial frictions & $\kappa$ & $\mathbb{N}$ & 3 \\
\hline cost volatility & $\sigma$ & $(0, \infty)$ & $0.05,0.1,0.15, \ldots, 0.45,0.5$ \\
\hline
\end{tabular}

Table 1: Parameterization.

To rule out parameterizations that are "uninteresting" for the purpose of investigating the impact of financial frictions, we consider the static Nash equilibrium $\left(p_{1}^{N}(\omega), p_{2}^{N}(\omega)\right)$ in state $\omega$ (see Appendix A and discard any parameterization for which financial frictions do not matter because $\pi_{1}\left(\omega, p_{1}^{N}(\omega), p_{2}^{N}(\omega)\right) \geq F_{0}$ for all $\omega$. This bounds $M$ and $\nu$ from above. We also bound $\sigma$ from above at 0.5 to marginalize the probability that investment outlays $F_{0}+\theta_{i}$ become negative. Finally, we discard any parameterization for which there is no meaningful investment absent financial frictions in the sense that $x_{1}(\omega)<0.01$ for all $\omega$.

\subsection{Homotopy method}

We use the homotopy or path-following method in Besanko, Doraszelski, Kryukov \& Satterthwaite (2010) to thoroughly explore the solution correspondence of our model and systematically search for multiple equilibria. The resulting computational demands were formidable. In total, we deployed more than 82,000 CPUs and spent 8.1 CPU years exploring the solution correspondence for the model with $\zeta=1$ and a further 7.4 CPU years exploring the solution correspondence of the model with $\zeta=0$.

To understand the homotopy method, consider solving a single equation $H(x, \rho)=$ 0 in a single variable $x$ that depends on a parameter $\rho$. To the extent that there is more than one value of $x$ that solves $H(x, \rho)=0$ for a given value of $\rho$, the mapping $H^{-1}(\rho)=\{x \mid H(x, \rho)=0\}$ from parameters into solutions is a correspondence. The homotopy method traces out this correspondence by introducing an auxiliary 
variable $s$ to construct the parametric path $(x(s), \rho(s)) \in H^{-1}(\rho)$. Differentiating $H(x(s), \rho(s))=0$ with respect to $s$ yields

$$
\frac{\partial H(x(s), \rho(s))}{\partial x} x^{\prime}(s)+\frac{\partial H(x(s), \rho(s))}{\partial \rho} \rho^{\prime}(s)=0 .
$$

Starting from any known point $(x(s), \rho(s))$ on the path, the so-called basic differential equation (16) prescribes how $x$ and $\rho$ must change to obtain another point on the path. Hence, the homotopy method reduces the task of solving the equation $H(x, \rho)=0$ to the task of solving the basic differential equation (16) given an initial condition in the form of a known point.

Exploring the solution correspondence of our model is more complex because it involves a system of $8 L+4$ equations $\mathcal{H}(\mathcal{X}, \boldsymbol{\rho})=0$ (Bellman equations and optimality conditions) in as many variables $\mathcal{X}$ (value and policy functions). Moreover, $\boldsymbol{\rho}$ is a vector in our model. We therefore compute slices of the solution correspondence by varying one of the key parameters at a time while holding the remaining parameters fixed. We denote a slice of the solution correspondence along, say, market size $M$ by $\mathcal{H}^{-1}(M)$, with the understanding that this slice also depends on the remaining parameters. We analogously construct slices $\mathcal{H}^{-1}(\nu), \mathcal{H}^{-1}(\tau)$, and $\mathcal{H}^{-1}(\sigma)$. A slice may consist of multiple disjoint paths, as illustrated by the slice $\mathcal{H}^{-1}(M)$ in the left panel of Figure 1 ப $^{6}$
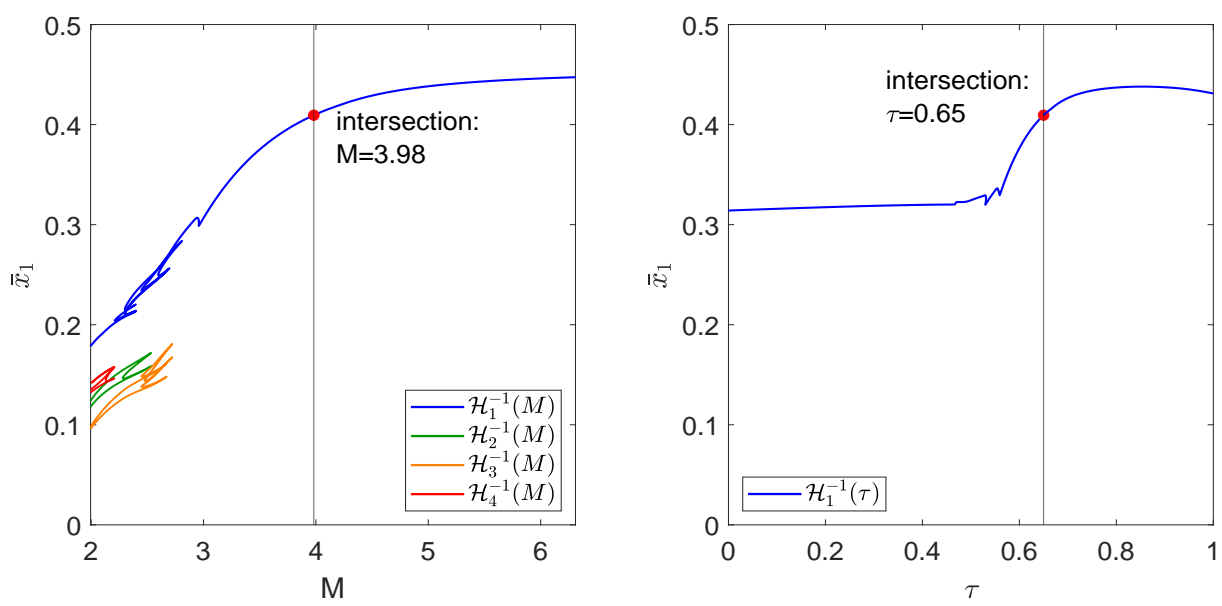

Figure 1: Example of solution correspondence, displayed as average investment probability $\bar{x}_{1}=\frac{1}{2 L+1} \sum_{\omega=-L}^{L} x_{1}(\omega)$. Slice $\mathcal{H}^{-1}(M)$ holding fixed $\nu=0.43, \tau=0.65$, and $\sigma=0.05$ (left panel) and slice $\mathcal{H}^{-1}(\tau)$ holding fixed $M=3.98, \nu=0.43$, and $\sigma=0.05$ (right panel). Model with $\zeta=1$.

\footnotetext{
${ }^{6}$ The paths in the left panel of Figure 1 appear not be disjoint because we display a one-dimensional summary statistic of $\mathcal{X}$ rather than $\mathcal{X}$ itself.
} 
Note that the slice $\mathcal{H}^{-1}(M)$ in the left panel of Figure 1 matches up with the slice $\mathcal{H}^{-1}(\tau)$ in the right panel, as indicated by the dots. We exploit this by "criss-crossing" the parameter space in an orderly fashion and using solutions on slices $\mathcal{H}^{-1}(M)$ as initial conditions to generate slices $\mathcal{H}^{-1}(\tau)$. Each slice $\mathcal{H}^{-1}(\tau)$ must either intersect with all already computed slices $\mathcal{H}^{-1}(M)$, or lead us to an additional solution that, in turn, gives us an initial condition to compute an additional slice $\mathcal{H}^{-1}(M)$. We continue this process until all slices $\mathcal{H}^{-1}(M)$ and $\mathcal{H}^{-1}(\tau)$ match up. We proceed similarly with the other key parameters $\nu$ and $\sigma$. In this way, we explore the solution correspondence over a four-dimensional hypercube in $(M, \nu, \tau, \sigma)$-space to compute as many solutions as possible.

While intuitively appealing, this process may nevertheless fail to compute all solutions. We refer the reader to Besanko et al. (2010) and Borkovsky, Doraszelski \& Kryukov $(2010,2012)$ for further details on the homotopy method.7

\subsection{Equilibria}

We computed 3,800,269 solutions over 91,158 out of 93,041 parameterizations for our baseline model 8 The number of solutions ranges from 1 to 23,200 across parameterizations. As discussed in Section 2.2, in the presence of financial frictions, a solution to the system of equations $\mathcal{H}(\mathcal{X}, \rho)=0$ is not necessarily an equilibrium. After checking that there is no profitable unilateral deviation, we retain 2,733,602 equilibria over 88,767 parameterizations. The number of equilibria ranges from 1 to 7,960 across parameterizations. Figure 2 depicts the number of equilibria at various parameterizations. As we can see, multiple equilibria are pervasive for larger values of market size $M$.

Multiple equilibria: intuition. Multiplicity is rooted in strategic investment behavior. This is easy to see in the special case of $\zeta=0$, where pricing decisions are uniquely determined by the static Nash equilibrium (see Appendix A) but multiple equilibria remain pervasive.

To build intuition, consider the investment stage in state $\omega$. Holding fixed continuation play, as given by their value functions, the firms play a one-shot game. Equation (8) defines the best reply of firm 1 to firm 2's investment probability $x_{2}(\omega)$ and implies that

$$
\frac{\partial x_{1}(\omega)}{\partial x_{2}(\omega)} \propto\left(V_{1}(\omega)-V_{1}\left(\omega^{-}\right)\right)-\left(V_{1}\left(\omega^{+}\right)-V_{1}(\omega)\right) .
$$

\footnotetext{
${ }^{7}$ We use the automatic differentiation package TAF (Giering, Kaminski \& Slawig 2005) to obtain the Jacobian of $\mathcal{H}(\mathcal{X}, \rho)$. Our codes are available upon request.

${ }^{8}$ The parameterizations for which we have been unable to compute a solution often involve low values of $\nu$. In the limit as $\nu \rightarrow 0$, demand in equation (2) becomes discontinuous. The homotopy method exploits the differentiability of the system of equations, as discussed in Section 3.2 .
} 

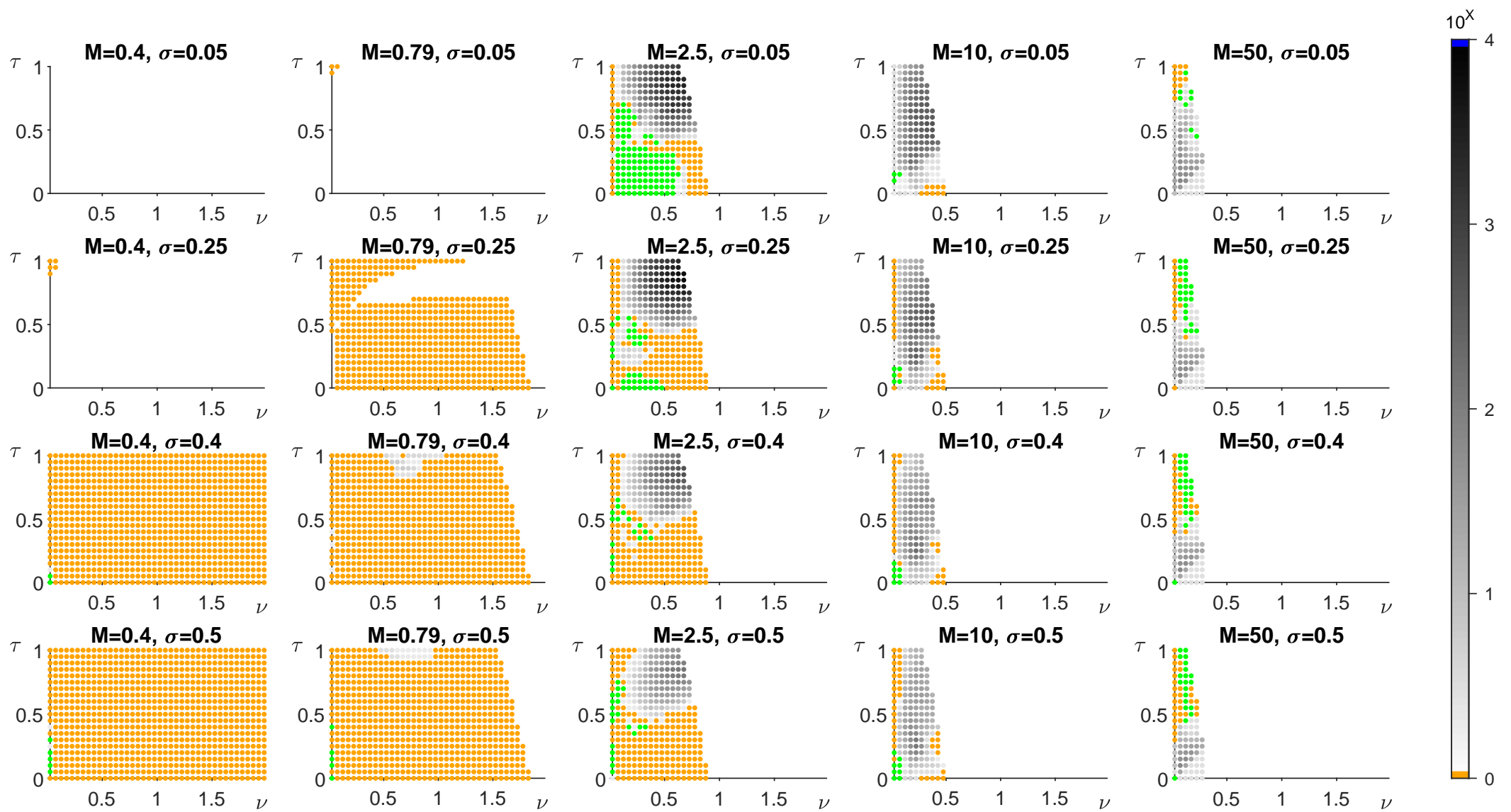

Figure 2: Number of equilibria. Orange indicates a unique equilibrium and darker shades of gray a larger number of equilibria. Green indicates no equilibrium and white a discarded (uninteresting) parameterization. Model with $\zeta=1$. 
Hence, if $V_{1}(\omega)$ is locally concave, then the best reply of firm 1 is upward-sloping and its investment is a strategic complement to that of firm 2. Conversely, if $V_{1}(\omega)$ is locally convex, then its investment is a strategic substitute to that of firm 2 .

In the limit as $\sigma \rightarrow 0$, we revert to mixed strategies and there are five cases to consider in this one-shot game:

1. Neither firm invests for sure, i.e., $x_{1}(\omega)=0$ and $x_{2}(\omega)=0$.

2. Firm 1 does not invest while firm 2 invests for sure, i.e., $x_{1}(\omega)=0$ and $x_{2}(\omega)=1$.

3. Firm 1 invests while firm 2 does not invest for sure, i.e., $x_{1}(\omega)=1$ and $x_{2}(\omega)=0$.

4. Both firms invest for sure, i.e., $x_{1}(\omega)=1$ and $x_{2}(\omega)=1$.

5. At least one firm mixes between investing and not investing, i.e., $0 \leq x_{1}(\omega) \leq 1$ and $0 \leq x_{2}(\omega) \leq 1$, with at least one strict inequality.

Cases 2, 3, and 5 can co-exist if the best replies of both firms are downward-sloping and thus can intersect more than once; this is the case of strategic substitutes. Conversely, cases 1, 4, and 5 can co-exist if the best replies of both firms are upward-sloping and thus can intersect more than once; this is the case of strategic complements.

The combination of $\zeta=0$ and $\sigma \rightarrow 0$ enables us to enumerate all equilibria by checking the $3 \cdot 5^{L-1} \cdot 3$ possible combinations of cases 1 through 5 for states $\omega \in\{0, \ldots, L\} 9^{9}$ The number of possible combinations increases exponentially in $L$. This suggests that the scope for multiple equilibria is vast once we set $L=15$.

Equilibrium behavior and industry dynamics. Multiplicity often does not lead to meaningful differences in the structure of the industry in the long run. However, Figure 3 shows that this is not always the case. For multiple equilibria in our baseline model with $M=5.01, \nu=0.33, \tau=0.55$, and $\sigma=0.50$, the figure depicts the pricing decision $p_{1}(\omega)$, profit $\pi_{1}\left(\omega, p_{1}(\omega), p_{2}(\omega)\right)$, investment probability $x_{1}(\omega)$, and limiting distribution $\mu^{\infty}(\omega)$. In both equilibria firm 1's pricing decision $p_{1}(\omega)$ diverges from static Nash pricing in some states $\omega$. Because $\pi_{1}\left(\omega, p_{1}(\omega), p_{2}(\omega)\right)<F_{0}$ in some states $\omega$, financial frictions matter and drive up the cost of investing $F\left(\pi_{1}(\cdot)\right)$.

Figure 3 shows that investment behavior and industry dynamics for the same primitives can be very different depending on the equilibrium. The equilibrium in the first row exhibits a pattern of increasing dominance. Firm 1's investment probability $x_{1}(\omega)$ is large in most states $\omega>0$, where firm 1 is the leader, and small in most states $\omega<0$, where firm 1 is the follower. Because $x_{2}(\omega)=x_{1}(-\omega)$ by symmetry, this means that in most states $\omega$ the leader invests more than the follower so that the expected change in the state $\omega$ in equation $(13)$ is $\Delta(\omega)>0$ if $\omega>0$ and $\Delta(\omega)<0$ if

\footnotetext{
${ }^{9}$ We can rule out cases 2 and 3 in state $\omega=0$ by symmetry. We can also rule out cases 3 and 4 in state $\omega=L$. Complete derivations for $L=1$ are available upon request.
} 

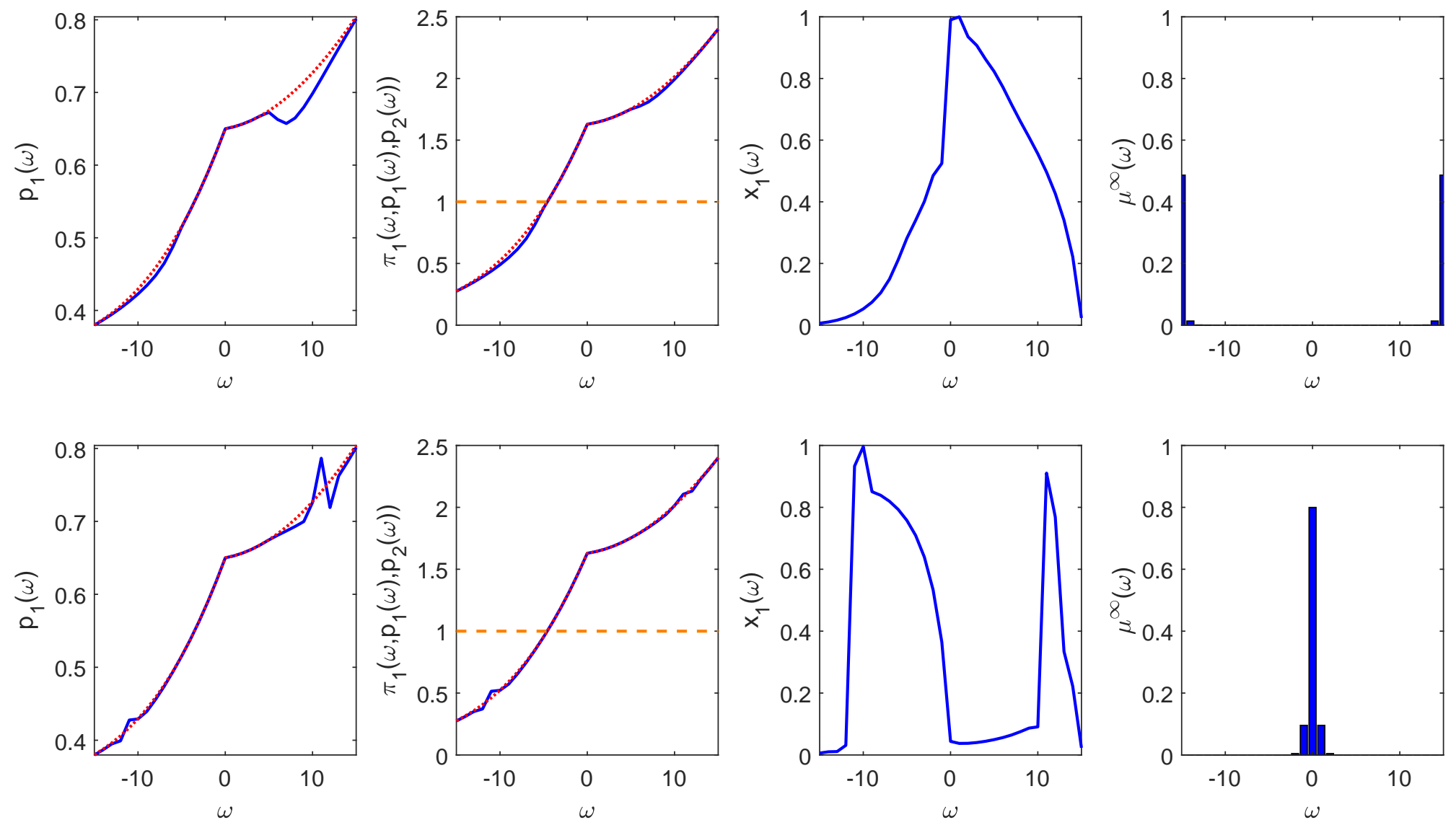

Figure 3: Example of multiple equilibria (first and second row). Pricing decision $p_{1}(\omega)$ (first column, solid line) overlayed by static Nash equilibrium (dotted line); profit $\pi_{1}\left(\omega, p_{1}(\omega), p_{2}(\omega)\right)$ (second column, solid line) overlayed by static Nash equilibrium (dotted line) and horizontal line at fixed cost $F_{0}=1$ (dashed lined); investment probability $x_{1}(\omega)$ (third column); and limiting distribution $\mu^{\infty}(\omega)$ (fourth column). Model with $M=5.01, \nu=0.33, \tau=0.55, \sigma=0.50$, and $\zeta=1$. 
$\omega<0$. As a result, the long-run industry structure is maximally asymmetric, with the limiting distribution $\mu^{\infty}(\omega)$ tightly concentrated around states $\omega=-L$ and $\omega=L$.

By contrast, the equilibrium in the second row exhibits catch-up behavior. Firm 1's investment probability $x_{1}(\omega)$ is large in most states $\omega<0$, where firm 1 is the follower, and small in most states $\omega>0$, where firm 1 is the leader. Because the expected change in the state $\omega$ is $\Delta(\omega)>0$ if $-12<\omega<0$ and $\Delta(\omega)<0$ if $0<\omega<12$, the long-run industry structure is minimally asymmetric, with the limiting distribution $\mu^{\infty}(\omega)$ tightly concentrated around state $\omega=0$.

Industry concentration. Figure 4 depicts the long-run industry structure as measured by the expected size of the competitive advantage $\bar{\omega}^{\infty}$ defined in equation (15) at various parameterizations. Because the literature offers little guidance regarding equilibrium selection, we view all equilibria that arise for the same primitives as equally likely. Accordingly, we average the value of $\bar{\omega}^{\infty}$ over all equilibria at a given parameterization.

As we can see, the long-run industry structure ranges from symmetric, with $\bar{\omega}^{\infty} \approx$ 0 , to maximally asymmetric, with $\bar{\omega}^{\infty} \approx 15$, depending on the parameterization. To assess the influence of fundamentals, we compute a finite-difference approximation to the partial derivative of $\bar{\omega}^{\infty}$ with respect to each of the four key demand and cost parameters $M, \nu, \tau$, and $\sigma 10$ The sign of this finite-difference approximation often depends on the parameterization, as we document in the Online appendix. Nevertheless, we find that a high value of the degree of horizontal product differentiation $\nu$ is a force towards symmetry in the long-run industry structure as is a low value of the leader handicap $\tau$. Intuitively, a higher $\nu$ softens price competition between the firms, while a lower $\tau$ imposes a greater disadvantage in the leader. A higher value of market size $M$ is also a force towards symmetry, albeit a weaker one. The value of cost volatility $\sigma$ has no discernible impact on the long-run industry structure.

As discussed earlier, industry dynamics hinge on whether the leader invests more or less than the follower. Figure 5 depicts the fraction of states where the leader invests more than the follower as measured by $\frac{1}{L} \sum_{\omega=1}^{L} 1\left[x_{1}(\omega)>x_{2}(\omega)\right]$, averaged over equilibria within parameterizations. Here and in what follows, we use $1[\cdot]$ to denote the indicator function. Comparing Figure 5 to Figure 4 shows that asymmetry in the long-run industry structure is more likely for parameterizations where the leader invests more than the follower in a large fraction of states. Conversely, symmetry in the long-run industry structure is more likely for parameterizations where the leader invests less than the follower in a large fraction of states 11 In the Online appendix

\footnotetext{
${ }^{10}$ In constructing the finite-difference approximation, we average the value of $\bar{\omega}^{\infty}$ over equilibria within parameterizations. We use adjacent points on the grid specified in Table 1 for the key parameters, a one-sided finite difference at the boundaries, and a two-sided finite difference in the interior.

${ }^{11}$ The fraction of states where the leader invests less than the follower is measured by $\frac{1}{L} \sum_{\omega=1}^{L} 1\left[x_{1}(\omega)<x_{2}(\omega)\right]=1-\frac{1}{L} \sum_{\omega=1}^{L} 1\left[x_{1}(\omega)>x_{2}(\omega)\right]$.
} 

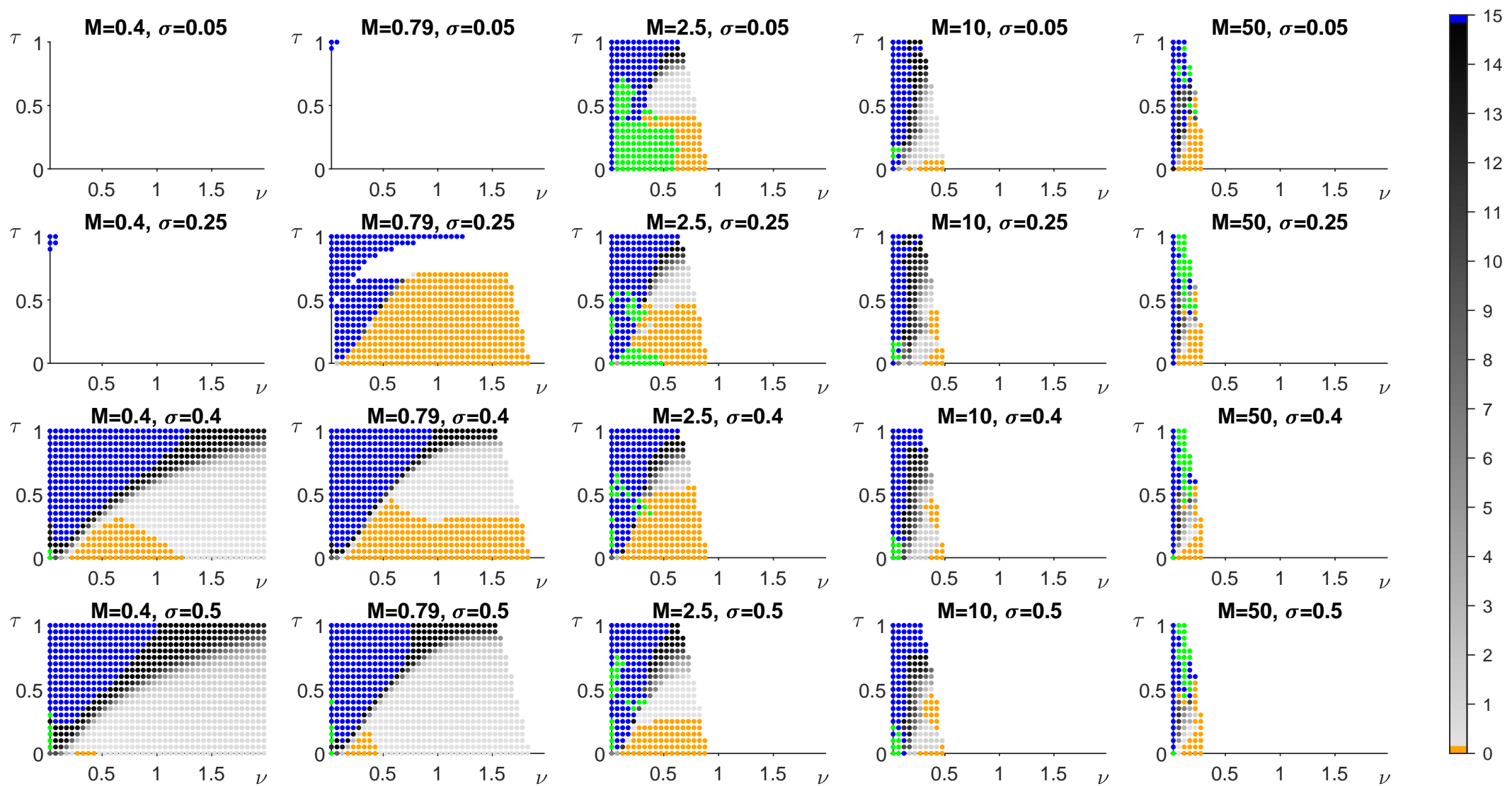

Figure 4: Long-run industry structure as measured by expected size of competitive advantage $\bar{\omega}^{\infty}$, averaged over equilibria within parameterizations. Orange indicates a symmetric industry, with $\bar{\omega}^{\infty} \in[0,0.01 L)$, and blue a maximally asymmetric industry, with $\bar{\omega}^{\infty} \in(0.99 L, L]$. In-between darker shades of gray indicate a more asymmetric industry. Green indicates no equilibrium and white a discarded (uninteresting) parameterization. Model with $\zeta=1$. 

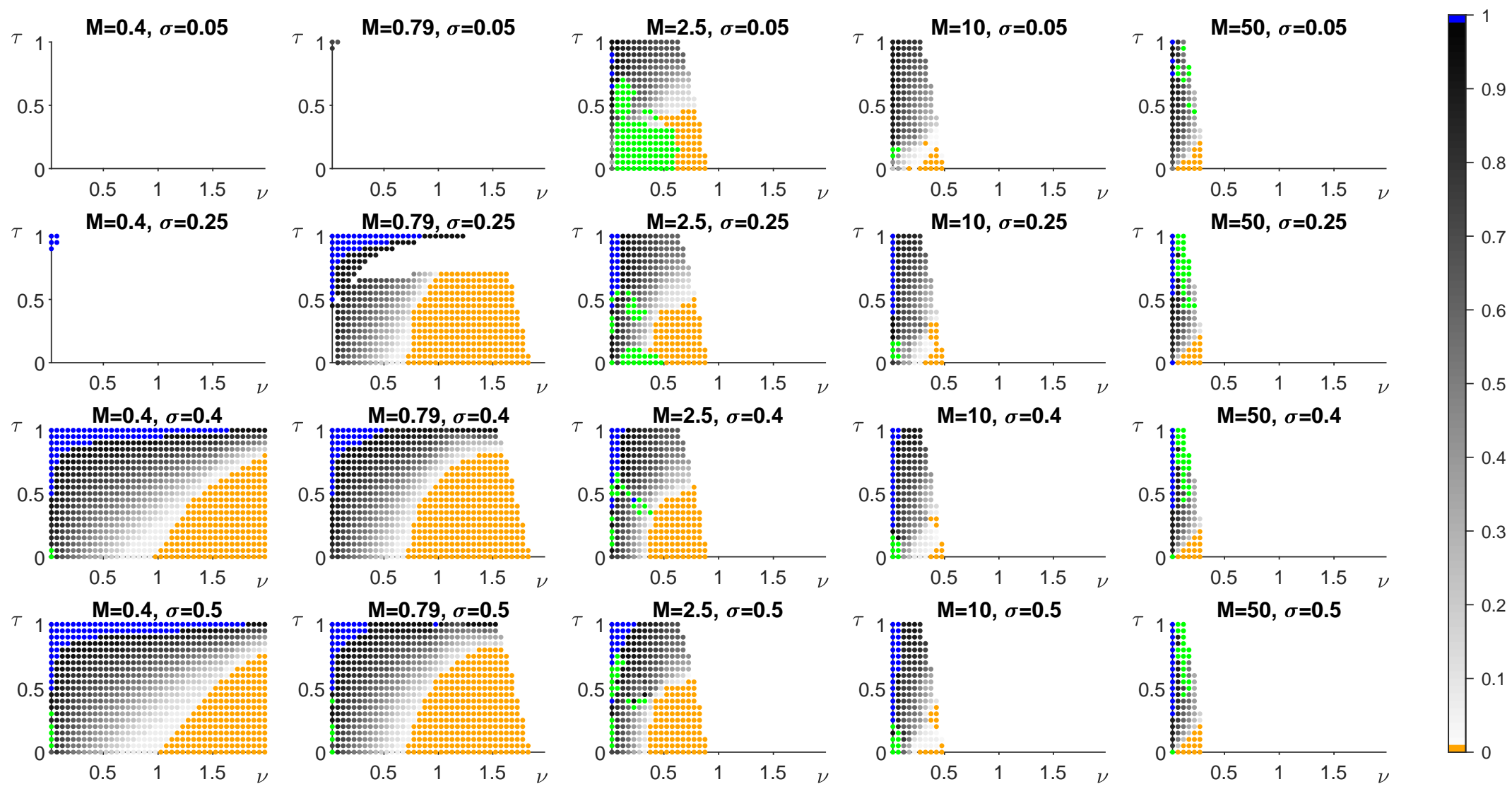

Figure 5: Fraction of states where leader invests more than follower as measured by $\frac{1}{L} \sum_{\omega=1}^{L} 1\left[x_{1}(\omega)>x_{2}(\omega)\right]$, averaged over equilibria within parameterizations. Orange indicates values below 0.01 and blue values above 0.99 . In-between darker shades of gray indicate larger values. Green indicates no equilibrium and white a discarded (uninteresting) parameterization. Model with $\zeta=1$. 
we visualize this correlation.

Joint-payoff effect. Budd et al. (1993) use a combination of asymptotic expansions and numerical analysis to argue that an industry tends to evolve towards the state where the joint payoff of the firms is largest. Our results show that this joint-payoff effect remains largely intact in the presence of financial frictions.

To see this intuitively, recall from equation (8) that $x_{1}(\omega)$ depends on the slope of the beginning-of-period value function of firm 1 around state $\omega$, namely $\beta\left[V_{1}\left(\omega^{+}\right)-V_{1}(\omega)\right]$ and $\beta\left[V_{1}(\omega)-V_{1}\left(\omega^{-}\right)\right]$. Similarly, $x_{2}(\omega)$ depends on $\beta\left[V_{2}\left(\omega^{-}\right)-V_{2}(\omega)\right]$ and $\beta\left[V_{2}(\omega)-V_{2}\left(\omega^{+}\right)\right]$. This suggests that we obtain $x_{1}(\omega)>x_{2}(\omega)$, so that the state tends to evolve towards $\omega^{+}$, if

$$
\begin{aligned}
& \beta\left[V_{1}\left(\omega^{+}\right)-V_{1}(\omega)\right]>\beta\left[V_{2}(\omega)-V_{2}\left(\omega^{+}\right)\right] \Longleftrightarrow V_{1}\left(\omega^{+}\right)+V_{2}\left(\omega^{+}\right)>V_{1}(\omega)+V_{2}(\omega), \\
& \beta\left[V_{1}(\omega)-V_{1}\left(\omega^{-}\right)\right]>\beta\left[V_{2}\left(\omega^{-}\right)-V_{2}(\omega)\right] \Longleftrightarrow V_{1}(\omega)+V_{2}(\omega)>V_{1}\left(\omega^{-}\right)+V_{2}\left(\omega^{-}\right) .
\end{aligned}
$$

Similarly, we obtain $x_{1}(\omega)<x_{2}(\omega)$, so that the state tends to evolve towards $\omega^{-}$, if the above inequalities are reversed. Thus, the state always tends to evolve in the direction where the joint payoff $V_{1}(\omega)+V_{2}(\omega)$ is larger.

To quantify the importance of the joint-payoff effect, we define

$$
\widehat{\omega}^{V}=\arg \max _{\omega \in\{0, \ldots, L\}} V_{1}(\omega)+V_{2}(\omega)
$$

as the state where the joint payoff of the firms is largest and compare it to the most likely long-run industry structure $\widehat{\omega}^{\infty}$ in equation (14). The left panel of Figure 6 shows the joint distribution over $\widehat{\omega}^{\infty}$ and $\widehat{\omega}^{V}$. The joint-payoff effect largely determines the long-run industry structure. There are only few equilibria in which $\widehat{\omega}^{\infty}>\widehat{\omega}^{V}$ and even fewer equilibria in which $\widehat{\omega}^{\infty}<\widehat{\omega}^{V}$.

To tie industry dynamics closer to primitives, we define

$$
\widehat{\omega}^{\pi}=\arg \max _{\omega \in\{0, \ldots, L\}} \pi_{1}\left(\omega, p_{1}^{N}(\omega), p_{2}^{N}(\omega)\right)+\pi_{2}\left(\omega, p_{1}^{N}(\omega), p_{2}^{N}(\omega)\right)
$$

as the state where the joint profit of the firms in the static Nash equilibrium (see Appendix A is largest. The right panel of Figure 6 shows the joint distribution over $\widehat{\omega}^{\infty}$ and $\widehat{\omega}^{\pi}$. As we can see, abstracting from the evolution of the industry over time and from investment and financing costs means that $\widehat{\omega}^{\pi}$ is slightly less predictive of $\widehat{\omega}^{\infty}$ than $\widehat{\omega}^{V}$.

Comparative statics. In the Online appendix we document a number of comparative statics results. In particular, we show that the average price charged by a firm $\bar{p}_{1}=\frac{1}{2 L+1} \sum_{\omega=-L}^{L} p_{1}(\omega)$ tends to increase in the value of the degree of horizontal product differentiation $\nu$ and, albeit to a smaller degree, in the value of the leader handicap $\tau$. The value of market size $M$ and the value of cost volatility $\sigma$ have no discernible impact on $\bar{p}_{1}$. 

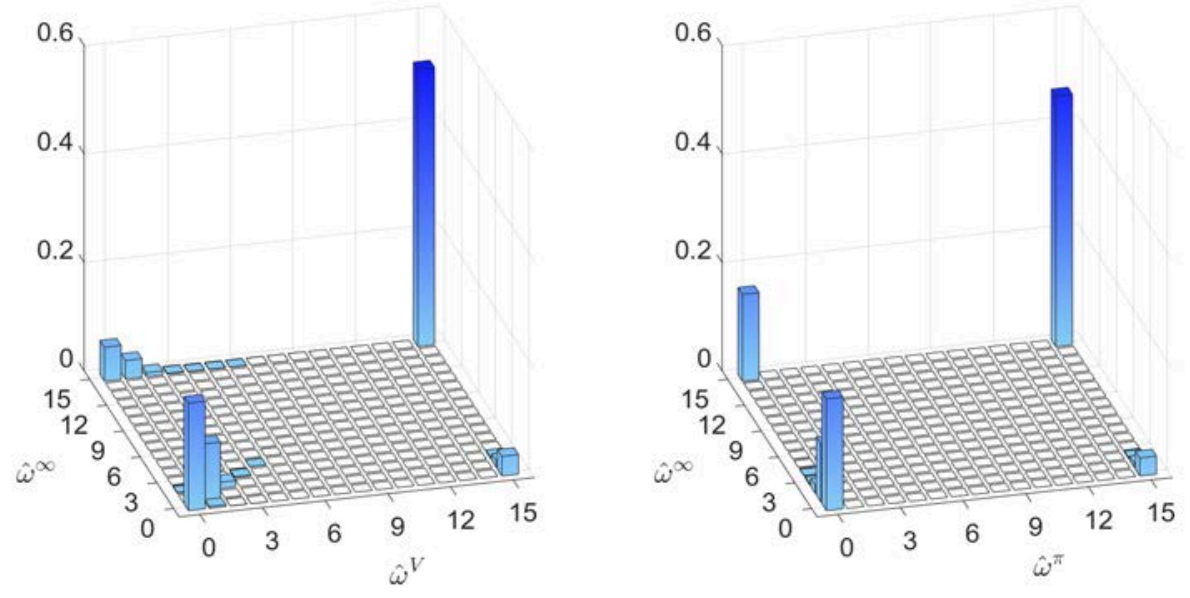

Figure 6: Joint-payoff effect. Joint distribution over most likely long-run industry structure $\widehat{\omega}^{\infty}$ and state $\widehat{\omega}^{V}$ where joint payoff is largest (left panel) respectively state $\widehat{\omega}^{\pi}$ where joint profit in static Nash equilibrium is largest (right panel). Model with $\zeta=1$.

We further show that the average investment probability $\bar{x}_{1}=\frac{1}{2 L+1} \sum_{\omega=-L}^{L} x_{1}(\omega)$ tends to increase in the value of $M$. The impact of $\sigma$ can be either positive or negative depending on the remaining parameters. By contrast, the impact of $\nu$ and $\tau$ depends on the firm's competitive position. While the leader's average investment probability $\bar{x}_{1}^{l}=\frac{1}{L} \sum_{\omega=1}^{L} x_{1}(\omega)$ tends to decrease in the value of $\nu$ and to increase in the value of $\tau$, the follower's average investment probability $\bar{x}_{1}^{f}=\frac{1}{L} \sum_{\omega=-L}^{-1} x_{1}(\omega)$ tends to increase in the value of $\nu$ and to decrease in the value of $\tau$.

Financial frictions. Figure 7 depicts the fraction of states where financial frictions matter as measured by $\frac{1}{2 L+1} \sum_{\omega=-L}^{L} 1\left[\pi_{1}\left(\omega, p_{1}(\omega), p_{2}(\omega)\right)<F_{0}\right]$, averaged over equilibria within parameterizations. A larger value of $M$ tends to alleviate financial frictions because profit increases with market size, as does a larger value of $\nu$ by softening price competition between the firms, and a larger value of $\tau$ by mitigating, or avoiding, the impact of the competitive disadvantage that the follower suffers on its profit. The value of $\sigma$ has no discernible impact on the fraction of states where financial frictions matter.

Because the profit of the leader exceeds that of the follower, financial frictions have a potentially greater impact on the follower. In the Online appendix we document this differential impact as measured by $\frac{1}{L} \sum_{\omega=-L}^{-1} 1\left[\pi_{1}\left(\omega, p_{1}(\omega), p_{2}(\omega)\right)<F_{0}\right]-$ $\frac{1}{L} \sum_{\omega=1}^{L} 1\left[\pi_{1}\left(\omega, p_{1}(\omega), p_{2}(\omega)\right)<F_{0}\right]$. For larger values of $M, \nu$, and $\tau$, financial frictions matter in a larger fraction of states for the follower than for the leader. 

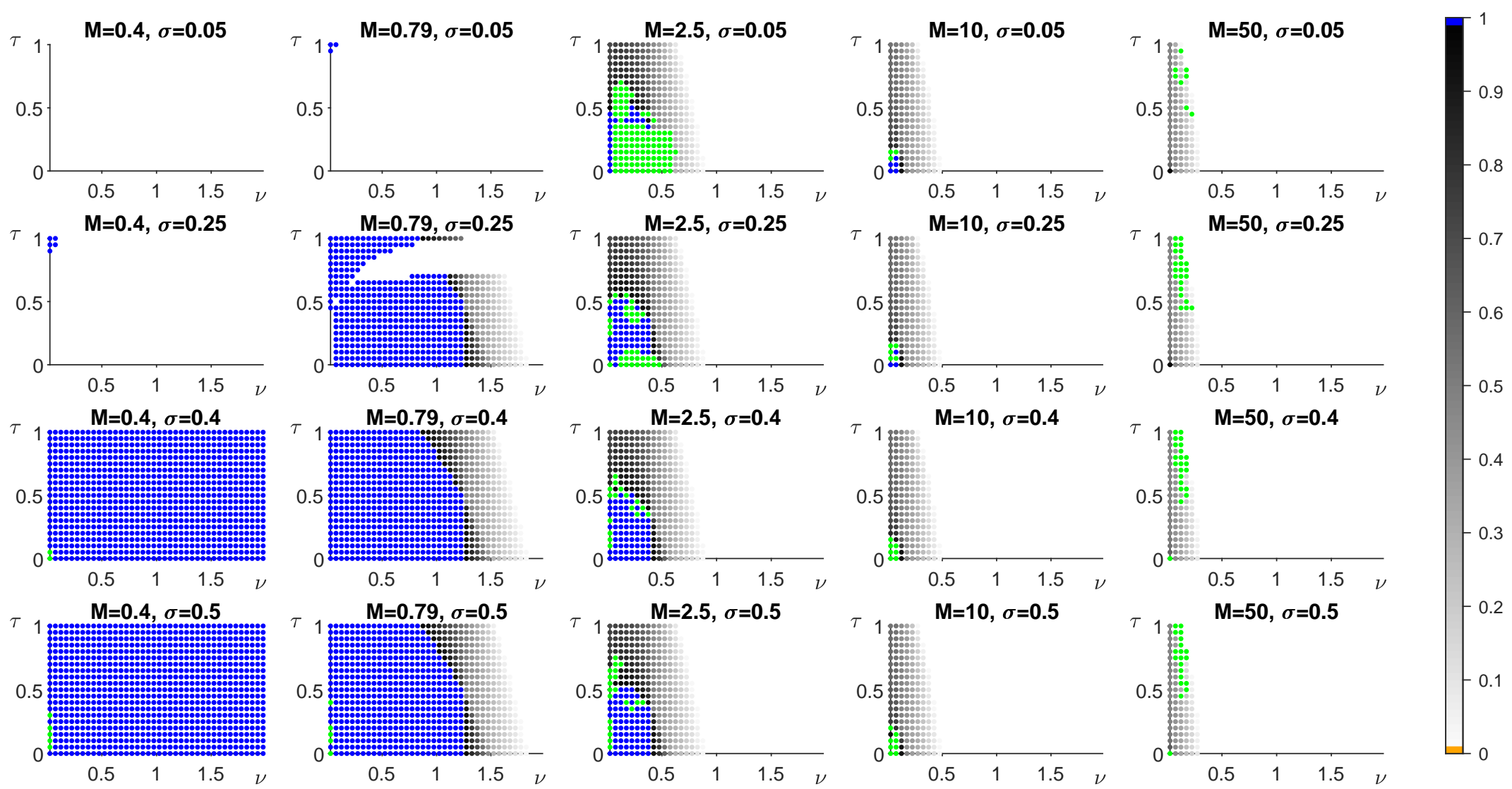

Figure 7: Fraction of states where financial frictions matter as measured by $\frac{1}{2 L+1} \sum_{\omega=-L}^{L} 1\left[\pi_{1}\left(\omega, p_{1}(\omega), p_{2}(\omega)\right)<F_{0}\right]$, averaged over equilibria within parameterizations. Orange indicates values below 0.01 and blue values above 0.99 . Inbetween darker shades of gray indicate larger values. Green indicates no equilibrium and white a discarded (uninteresting) parameterization. Model with $\zeta=1$. 


\section{Impact of financial frictions}

Financial frictions can affect price, investment, and industry concentration. To understand these effects, we juxtapose the equilibria that arise in our baseline model to the equilibria that arise in the special case of $\zeta=0$. For brevity, we henceforth refer to the former as equilibria with financial frictions and to the latter as equilibria without financial frictions. We use the superscripts $F C$ respectively $N O F C$ to distinguish them.

In line with our choice not to engage in equilibrium selection, we form all possible pairs of equilibria with and without frictions at a given parameterization. This leaves us with 2,864,517,460 pairs over 88,767 parameterizations, with the number of pairs ranging from 1 to 47,019,720 across parameterizations. To account for this wide range, in what follows we average a statistic of interest over all pairs at a given parameterization.

\subsection{Impact on price}

To investigate the impact of financial frictions on price, we compute

$$
1\left[p_{1}^{F C}(\omega)<p_{1}^{N O F C}(\omega)-0.01\left\|p_{1}^{N O F C}\right\| \text { for some } \omega\right]
$$

and

$$
1\left[p_{1}^{F C}(\omega)>p_{1}^{N O F C}(\omega)+0.01\left\|p_{1}^{N O F C}\right\| \text { for some } \omega\right],
$$

where $p_{1}^{F C}(\omega)$ is firm 1's pricing decision in state $\omega$ in the baseline model, $p_{1}^{\text {NOFC }}(\omega)$ is firm 1's pricing decision in state $\omega$ in the special case of $\zeta=0$, and the factor $0.01\left\|p_{1}^{N O F C}\right\|=\frac{0.01}{2 L+1} \sum_{\omega=-L}^{L}\left|p_{1}^{N O F C}(\omega)\right|$ ensures that we focus only on economically meaningful differences. The following result summarizes our findings.

Result 1 We find that financial frictions:

(a) decrease price in all pairs of equilibria with and without financial frictions at 17.6\% of parameterizations and in at least some pairs at 28.5\% of parameterizations;

(b) increase price in all pairs of equilibria with and without financial frictions at $11.8 \%$ of parameterizations and in at least some pairs at $24.8 \%$ of parameterizations.

As discussed in Section 2.1, the combination of financial frictions and strategic interactions has profound implications for pricing decisions. In our baseline model, firm 1 deviates from static Nash pricing to the extent that this allows it to influence firm 2's investment probability $x_{2}(\omega)$ through influencing $\pi_{1}(\cdot)$ or $\pi_{2}(\cdot)$.

Figure 8 shows the regions of parameter space where financial frictions decrease price as per part (a) of Result 1. These deviations from static Nash pricing tend to occur for intermediate values of market size $M$, low values of the degree of horizontal product differentiation $\nu$, and for high values of the leader handicap $\tau$ and cost volatility $\sigma$, although the impact of $\nu$ and $\tau$ is more muted. 
It is perhaps not surprising that financial frictions can decrease price, since by decreasing price a firm can decrease its rival's profit. In the presence of financial frictions, this can drive up the rival's cost of investing, although it also decreases the firm's profit and, thus, can drive up its own cost of investing.

As the leader's profit is always higher than the follower's profit, the leader can more often afford to decrease price without incurring additional financing costs to fund investment. Specifically, we find that financial frictions decrease the leader's price in at least some pairs of equilibria at $27.5 \%$ of parameterizations and the follower's price in at least some pairs of equilibria at $24.5 \%$ of parameterizations. ${ }^{12}$

Part (b) of Result 1 shows that financial frictions can lead to higher prices. In the Online appendix we document that this tends to occur for intermediate values of $M$, for low values of $\nu$ and $\tau$, and for high values of $\sigma$, although the impact of $\tau$ and $\sigma$ is more muted. We return below to the issue of why financial frictions can increase price when discussing the connection between price and investment decisions.

Profitability. As financial frictions affect not only price but also the evolution of the industry over time, a price decrease in a given period may be offset by a price increase in a later period. We therefore compute the expected net present value of industry-wide profit

$$
\Pi^{\infty}=E\left[\sum_{t=0}^{\infty} \beta^{t}\left(\pi_{1}\left(\omega^{t}, p_{1}\left(\omega^{t}\right), p_{2}\left(\omega^{t}\right)\right)+\pi_{2}\left(\omega^{t}, p_{1}\left(\omega^{t}\right), p_{2}\left(\omega^{t}\right)\right)\right) \mid \omega^{0}=0\right],
$$

where the expectation is with respect to the Markov chain defined by equation (12) and the initial state is $\omega^{0}=0$. Similar to our analysis of price, we compute

$$
1\left[\Pi^{\infty, F C}<\Pi^{\infty, N O F C}-0.01 \frac{\left\|\pi_{1}^{N O F C}+\pi_{2}^{N O F C}\right\|}{1-\beta}\right]
$$

and

$$
1\left[\Pi^{\infty, F C}>\Pi^{\infty, N O F C}+0.01 \frac{\left\|\pi_{1}^{N O F C}+\pi_{2}^{N O F C}\right\|}{1-\beta}\right] .
$$

The following result summarizes our findings.

Result 2 We find that financial frictions:

(a) decrease the profitability of product market competition in all pairs of equilibria with and without financial frictions at $3.7 \%$ of parameterizations and in at least some pairs at $24.5 \%$ of parameterizations;

(b) increase the profitability of product market competition in all pairs of equilibria with and without financial frictions at $14.4 \%$ of parameterizations and in at least some pairs at $34.4 \%$ of parameterizations.

\footnotetext{
${ }^{12}$ In the Online appendix we document the (largely overlapping) regions of the parameter space where financial frictions decrease the leader's price or the follower's price as well as where financial frictions decrease price when the firms compete head-to-head.
} 

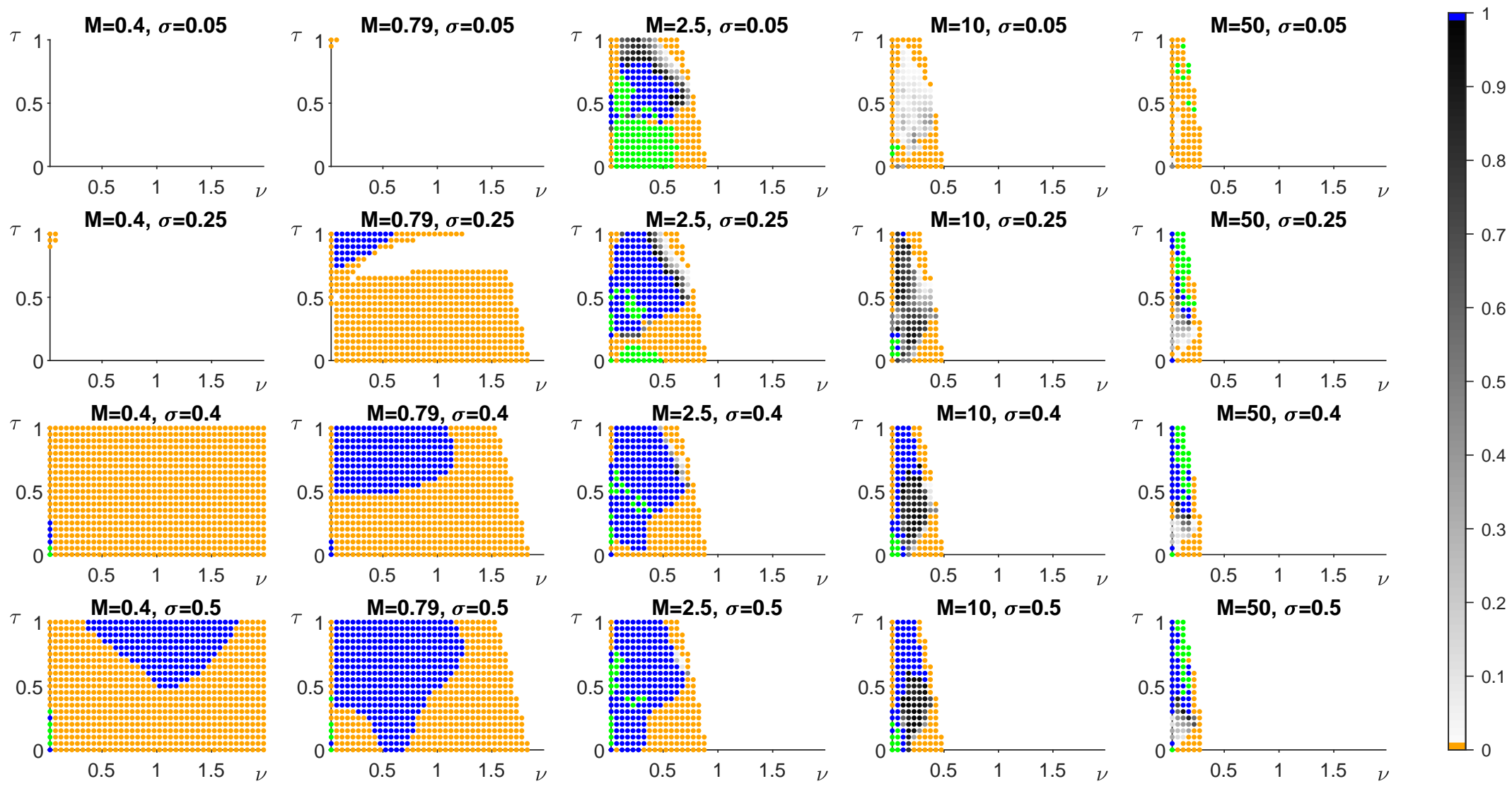

Figure 8: Financial frictions decrease price as measured by $1\left[p_{1}^{F C}(\omega)<p_{1}^{N O F C}(\omega)-0.01\left\|p_{1}^{N O F C}\right\|\right.$ for some $\left.\omega\right]$, averaged over pairs of equilibria with and without financial frictions within parameterizations. Orange indicates values below 0.01 and blue values above 0.99. In-between darker shades of gray indicate larger values. Green indicates no pair of equilibria with and without financial frictions and white a discarded (uninteresting) parameterization. 
Hence, even though the impact of financial frictions is skewed towards decreasing price, it is skewed towards increasing the profitability of product market competition. In the Online appendix we document that financial frictions tend to decrease the profitability of product market competition for intermediate values of $M$ and for high values of $\tau$ and $\sigma$, although the impact of $\tau$ and $\sigma$ is more muted. The impact of $\nu$ depends on the remaining parameters. Financial frictions tend to increase the profitability of product market competition for low values of $M, \nu$, and $\tau$ and for high values of $\sigma$, although the impact of $M, \tau$, and $\sigma$ is more muted.

\subsection{Impact on investment}

Because they directly increase the cost of investing, financial frictions often lead to lower investment. This is the core intuition from the single-firm models widely used in corporate finance. Here, however, we show that the combination of financial frictions and strategic interactions can also lead to higher investment.

To understand the impact of financial frictions on investment, we compute

$$
1\left[x_{1}^{F C}(\omega)<x_{1}^{N O F C}(\omega)-0.01\left\|x_{1}^{N O F C}\right\| \text { for some } \omega\right]
$$

and

$$
1\left[x_{1}^{F C}(\omega)>x_{1}^{N O F C}(\omega)+0.01\left\|x_{1}^{N O F C}\right\| \text { for some } \omega\right] .
$$

The following result summarizes our findings.

Result 3 We find that financial frictions:

(a) decrease investment in all pairs of equilibria with and without financial frictions at $82.3 \%$ of parameterizations and in at least some pairs at $96.0 \%$ of parameterizations;

(b) increase investment in all pairs of equilibria with and without financial frictions at $14.3 \%$ of parameterizations and in at least some pairs at $34.0 \%$ of parameterizations.

Part (a) of Result 3 indicates that the intuition from single-firm models often carries over to our model. In the Online appendix we document that financial frictions tend to decrease investment for low values of market size $M$ and the degree of horizontal product differentiation $\nu$ and for high values for the leader handicap $\tau$, although the impact of $\tau$ is more muted. The impact of cost volatility $\sigma$ depends on the remaining parameters.

Notably, financial frictions can also increase investment as part (b) of Result 3 indicates. Figure 9 shows the regions of parameter space where this occurs. As we can see, financial frictions tend to increase investment for intermediate values for $M$ and for high values of $\tau$. The impact of $\nu$ and $\sigma$ is more muted and depends on the remaining parameters.

Financial frictions are slightly more likely to increase the leader's investment (in at least some pairs of equilibria at $30.9 \%$ of parameterizations) than the follower's 

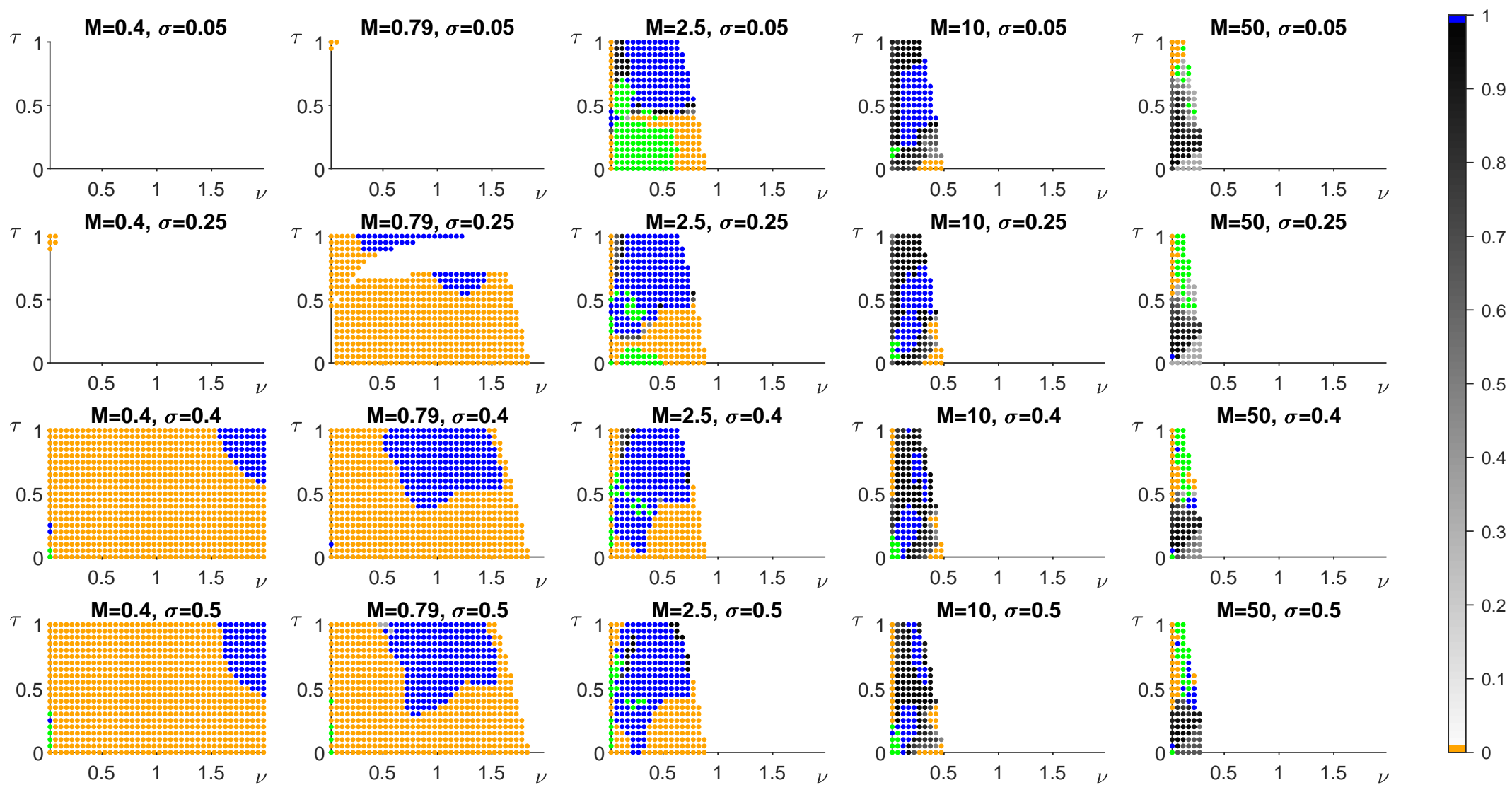

Figure 9: Financial frictions increase investment as measured by $1\left[x_{1}^{F C}(\omega)>x_{1}^{N O F C}(\omega)+0.01\left\|x_{1}^{N O F C}\right\|\right.$ for some $\left.\omega\right]$, averaged over pairs of equilibria with and without financial frictions within parameterizations. Orange indicates values below 0.01 and blue values above 0.99. In-between darker shades of gray indicate larger values. Green indicates no pair of equilibria with and without financial frictions and white a discarded (uninteresting) parameterization. 
investment (27.3\% of parameterizations) ${ }^{13}$ The combination of financial frictions and strategic interactions creates an additional incentive to invest: if by investing in the current period a firm can decrease its rival's profit in the subsequent period, then this can drive up the rival's cost of investing ${ }^{14}$ In this sense, a firm can exploit financial frictions to entrench its competitive position.

Connection between price and investment decisions. Comparing Figure 8 and Figure 9 shows that parameterizations for which investment is higher in the presence of financial frictions frequently coincide with those for which price is lower, notably for larger values of market size $M$. Similarly, parameterizations for which investment is lower in the presence of financial frictions frequently coincide with those for which price is higher. In the Online appendix we visualize these correlations.

Figure 10 shows an example of how strategic pricing and investment behavior can interact in multiple equilibria for our baseline model with $M=7.94, \nu=0.18$, $\tau=0.15$, and $\sigma=0.05$. Recall that symmetry implies that the behavior of firm 2 in state $\omega$ is the same as that of firm 1 in state $-\omega$ and that price and profit in an equilibrium without financial frictions are the same as those in the static Nash equilibrium (see Appendix A).

As we can see, profit $\pi_{1}\left(\omega, p_{1}^{N O F C}(\omega), p_{2}^{N O F C}(\omega)\right)$ is flatter in state $\omega$ than in state $-\omega$ if $0<\omega<10$. This suggests that the leader (firm 1) has a smaller incentive to invest than the follower (firm 2) if $0<\omega<10$. On the other hand, if $\omega \geq 10$, profit $\pi_{1}\left(\omega, p_{1}^{N O F C}(\omega), p_{2}^{N O F C}(\omega)\right)$ is steeper in state $\omega$ than in state $-\omega$ and the leader has a larger incentive to invest than the follower. In the first row of Figure 10 , price and profit in the equilibrium with financial frictions differ only slightly from those in the equilibrium without financial fictions. In the equilibrium with financial frictions, the industry becomes maximally asymmetric in the long run. Note that the leader's profit is smaller in state $\omega=L$ than in state $\omega=0$.

In the second row, price and profit in the equilibrium with financial frictions differ much more from those in the equilibrium without financial fictions. In particular, in the equilibrium with financial frictions the leader (firm 1) significantly increases its price in state $\omega=12$, thereby shifting demand to the follower (firm 2). As a consequence, the leader's profit in state $\omega=12$ decreases while the follower's profit increases. This, in turn, decreases the follower's cost of investing in state $\omega=12$ and sufficiently increases the follower's incentive to invest in nearby states to ensure that the industry remains symmetric in the long run.

\footnotetext{
${ }^{13}$ In the Online appendix we document the (somewhat overlapping) regions of the parameter space where financial frictions increase the leader's investment or the follower's investment. We also document that in some cases financial frictions can increase investment when the firms compete head-tohead.

${ }^{14}$ As Figure 3 shows, profit $\pi_{1}\left(\omega, p_{1}^{F C}(\omega), p_{2}^{F C}(\omega)\right)$ may not be monotonic in the state $\omega$. Nonmonotonicity tends to occur for low values of $\tau$.
} 

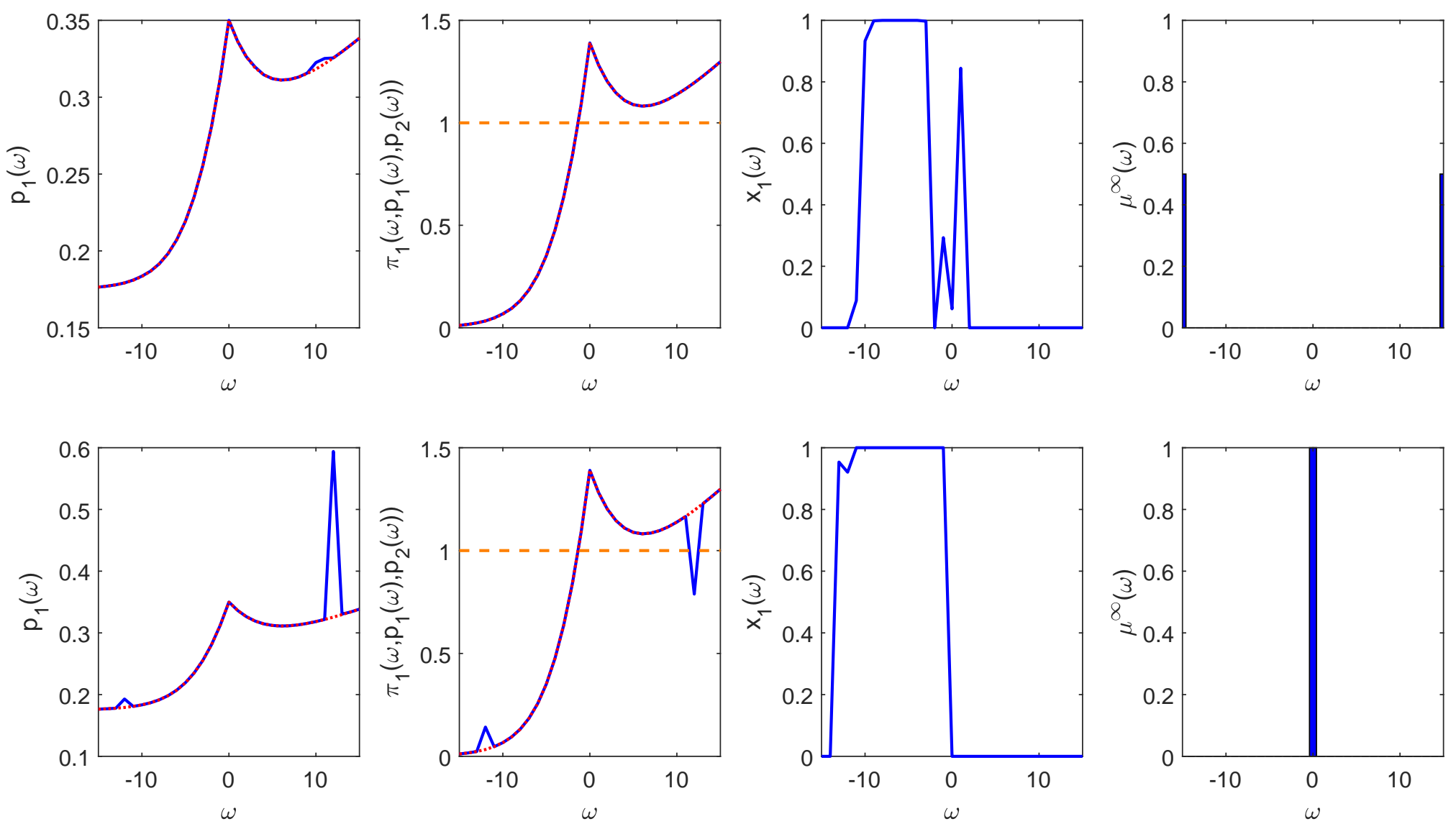

Figure 10: Example of multiple equilibria with price increase (first and second row). Pricing decision $p_{1}^{F C}(\omega)$ (first column, solid line) overlayed by $p_{1}^{N O F C}(\omega)$ (dotted line); profit $\pi_{1}\left(\omega, p_{1}^{F C}(\omega), p_{2}^{F C}(\omega)\right)$ (second column, solid line) overlayed by $\pi_{1}\left(\omega, p_{1}^{N O F C}(\omega), p_{2}^{N O F C}(\omega)\right)$ (dotted line) and horizontal line at fixed cost $F_{0}=1$ (dashed lined); investment probability $x_{1}^{F C}(\omega)$ (third column); and limiting distribution $\mu^{\infty, F C}(\omega)$ (fourth column). Model with $M=7.94, \nu=0.18, \tau=0.15$, $\sigma=0.05$, and $\zeta=1$. 


\subsection{Impact on industry concentration}

Financial frictions can increase or decrease the degree of industry concentration in the long run. To understand the impact of financial frictions on long-run industry concentration, we compute the difference in the expected size of the competitive advantage $\bar{\omega}^{\infty, F C}-\bar{\omega}^{\infty, N O F C}$, averaged over pairs of equilibria with and without financial frictions within parameterizations. The following result summarizes our findings ${ }^{15}$

Result 4 We find that financial frictions:

(a) decrease long-run industry concentration in all pairs of equilibria with and without financial frictions at $4.2 \%$ of parameterizations and in at least some pairs at $17.7 \%$ of parameterizations;

(b) increase long-run industry concentration in all pairs of equilibria with and without financial frictions at $40.0 \%$ of parameterizations and in at least some pairs at $56.3 \%$ of parameterizations.

Financial frictions often do not change long-run industry concentration. When they do matter, however, they more often exacerbate asymmetries between firms over time, allowing one firm to eventually become dominant.

Figure 11 depicts the difference in the expected size of the competitive advantage $\bar{\omega}^{\infty, F C}-\bar{\omega}^{\infty, N O F C}$ at various parameterizations. Not surprisingly, these differences tend to be more pronounced in the regions of the parameter space where financial frictions matter more. In the Online appendix we visualize this correlation.

Figure 11 also illustrates that, occasionally, financial frictions mitigate asymmetries between firms over time. However, as Figure 12 shows, while increases in long-run industry concentration can be sizeable, decreases in industry concentration tend to be fairly small.

Speed of convergence. Even if financial frictions do not change long-run industry concentration, they can impact the speed of convergence to the limiting distribution. To understand this effect, we define the total variation distance between the transient distribution $\mu_{\omega^{0}}^{25}(\omega)$ after 25 periods and starting from initial state $\omega^{0}$ and the limiting distribution $\mu^{\infty}(\omega)$ as

$$
\delta=\frac{\sum_{\omega=-L}^{L}\left|\mu_{\omega^{0}}^{25}(\omega)-\mu^{\infty}(\omega)\right|}{2} .
$$

A larger value of $\delta$ implies slower convergence to the limiting distribution, and we measure the impact of financial frictions on the speed of convergence as $\delta^{F C}-\delta^{N O F C}$. To focus on the most interesting cases, we form all possible pairs of equilibria with financial frictions and $\bar{\omega}^{\infty, F C} \geq 0.99 \mathrm{~L}$ and equilibria without financial frictions and $\bar{\omega}^{\infty, N O F C} \geq 0.99 \mathrm{~L}$. We also form all possible pairs of equilibria with financial frictions and $\bar{\omega}^{\infty, F C} \leq 0.01 \mathrm{~L}$ and equilibria without financial frictions and $\bar{\omega}^{\infty, N O F C} \leq 0.01 \mathrm{~L}$.

\footnotetext{
${ }^{15}$ These comparisons are all up to a factor $0.01 \mathrm{~L}$ to ensure economically meaningful differences.
} 

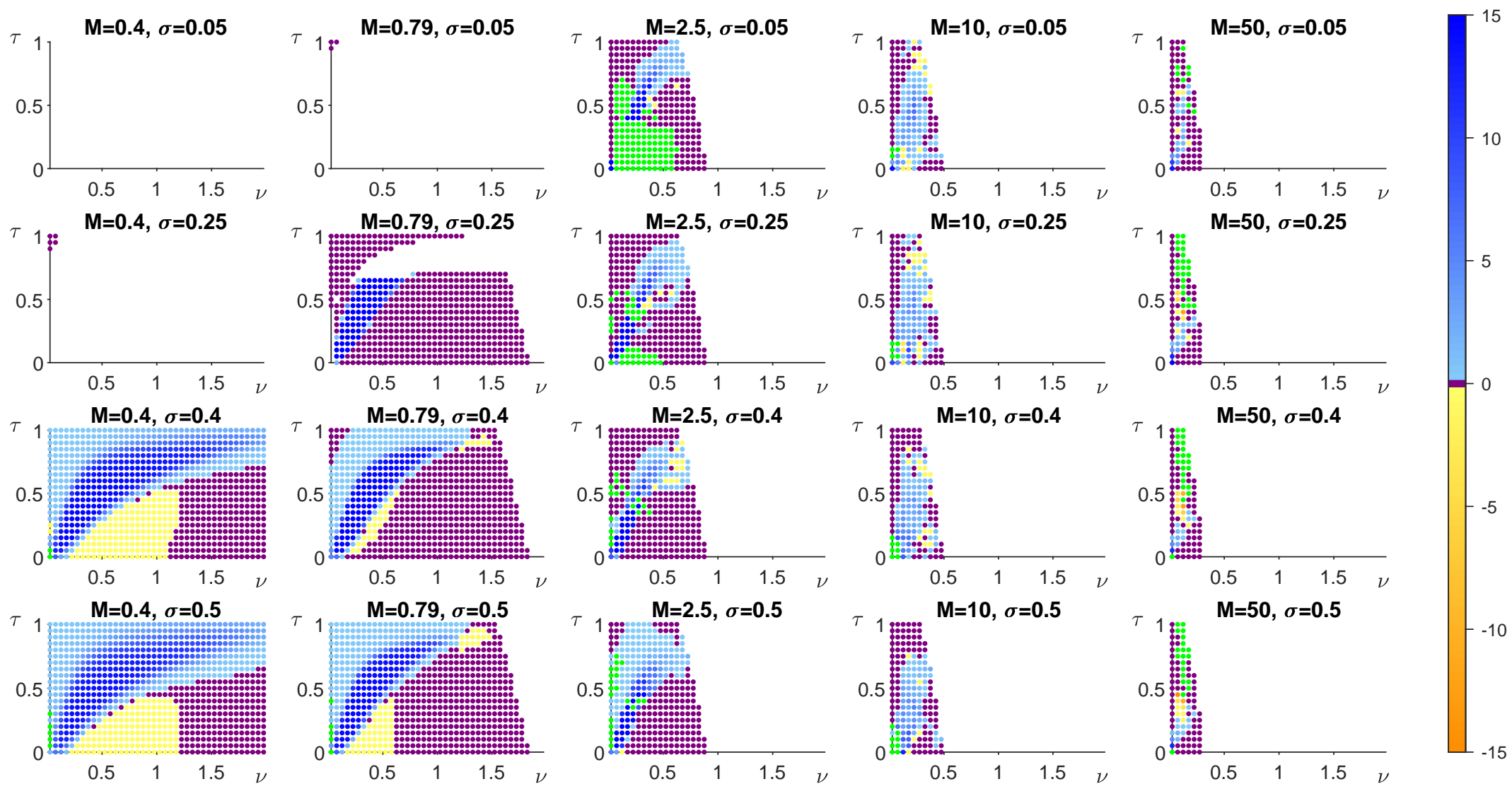

Figure 11: Difference in expected size of competitive advantage $\bar{\omega}^{\infty, F C}-\bar{\omega}^{\infty, N O F C}$, averaged over pairs of equilibria with and without financial frictions within parameterizations. Darker shades of blue indicate a more asymmetric industry with financial frictions. Darker shades of orange indicate a more symmetric industry with financial frictions. Purple indicates no economically meaningful difference (band of width of $0.01 \mathrm{~L}$ centered around zero). Green indicates no pair of equilibria and white a discarded (uninteresting) parameterization. 


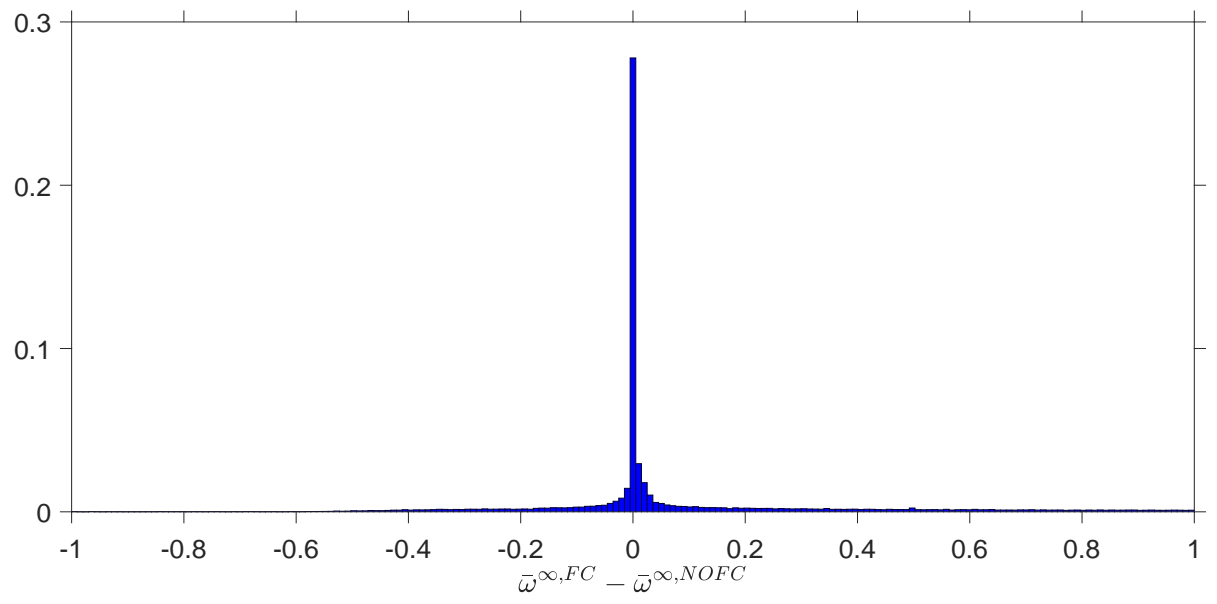

Figure 12: Distribution over difference in expected size of competitive advantage $\bar{\omega}^{\infty, F C}-\bar{\omega}^{\infty, N O F C}$, averaged over pairs of equilibria with and without financial frictions within parameterizations.

In the former case, because the industry becomes maximally asymmetric we choose $\omega^{0}=0$; in the latter case, because the industry becomes symmetric we choose $\omega^{0}=L$. The following result summarizes our findings. ${ }^{16}$

Result 5 We find that financial frictions:

(a) do not change the speed of convergence towards symmetric industries in any pair of equilibria with financial frictions and $\bar{\omega}^{\infty, F C} \leq 0.01 \mathrm{~L}$ and equilibria without financial frictions and $\bar{\omega}^{\infty, N O F C} \leq 0.01 L$

(b) increase the speed of convergence towards maximally asymmetric industries in at least some pairs of equilibria with financial frictions and $\bar{\omega}^{\infty, F C} \geq 0.99 \mathrm{~L}$ and equilibria without financial frictions and $\bar{\omega}^{\infty, N O F C} \geq 0.99 \mathrm{~L}$ at $16.46 \%$ of parameterizations;

(c) decrease the speed of convergence towards maximally asymmetric industries in at least some pairs of equilibria with financial frictions and $\bar{\omega}^{\infty, F C} \geq 0.99 \mathrm{~L}$ and equilibria without financial frictions and $\bar{\omega}^{\infty, N O F C} \geq 0.99 \mathrm{~L}$ at $3.93 \%$ of parameterizations.

Figure 13 illustrates the impact of financial frictions on the speed of convergence towards maximally asymmetric industries as per parts (b) and (c) of Result 5 for various parameterizations. As we can see, for pairs of equilibria with and without financial frictions that imply that the industry becomes maximally asymmetric, financial frictions more often accelerate than decelerate convergence to the limiting distribution

\footnotetext{
${ }^{16}$ These comparisons are all up to a factor 0.01 to ensure economically meaningful differences.
} 

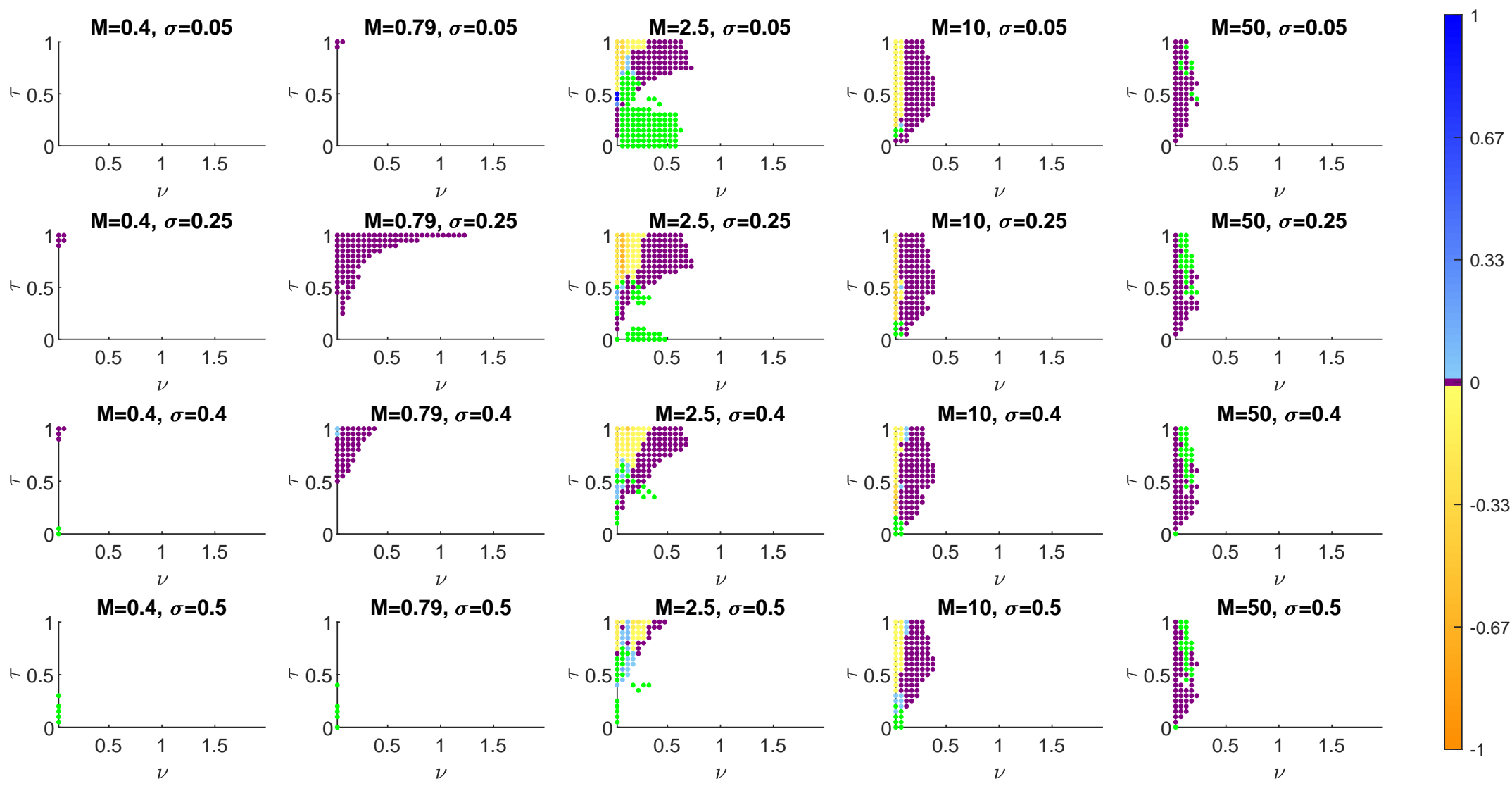

Figure 13: Difference in speed of convergence as measured by $\delta^{F C}-\delta^{N O F C}$, averaged over pairs of equilibria with financial frictions and $\bar{\omega}^{\infty, F C} \geq 0.99 L$ and equilibria without financial frictions and $\bar{\omega}^{\infty, N O F C} \geq 0.99 L$ within parameterizations. Darker shades of blue indicate slower convergence with financial frictions. Darker shades of orange indicate faster convergence with financial frictions. Purple indicates no economically meaningful difference (band of width of 0.01 centered around zero). Green indicates no pair of equilibria and white a discarded (uninteresting) parameterization. 


\section{Concluding remarks}

Although limitations in the access to capital markets play a key role for firms' pricing and investment strategies and the evolution of industries over time, virtually all extant literature in industrial organization assumes perfect capital markets, where every NPV-positive investment project can be funded in a costless way. On the other hand, the extant literature in corporate finance almost always assumes away strategic interactions between firms. In this paper, we bridge this gap by developing and analyzing a benchmark theoretical setting that integrates core corporate finance insights about the impact of financial frictions on investment with those from industrial organization on dynamic competition and industry evolution under perfect capital markets.

We show that accounting for strategic interactions can be of first-order importance for our understanding of the impact of financial frictions. Using state of the art computational tools to systematically detect and evaluate multiple equilibria and to thoroughly explore the parameter space of our model, we show how, depending on key industry characteristics such as market size, the degree of product differentiation, and the level of possible regulatory intervention, financial frictions may lead firms to charge lower or higher prices and to invest more or less. Financial frictions may also cause an industry to become more or less concentrated over time.

Our findings indicate that financial frictions are consequential for the industrial organization literature. Beyond their significant quantitative effects, financial frictions imply that firms' pricing decisions can no longer be understood and analyzed separately from their investment decisions. This is because prices and profits directly impact the effective cost of tapping capital markets to raise external funds and, thus, how the industry evolves over time.

At the same time, our findings call for rethinking large parts of the corporate finance literature that assumes away strategic interactions between firms. The realization that in several cases the dynamic strategic interactions between firms actually lead firms to invest more in the presence of financial frictions is at odds with almost all extant work in corporate finance and challenges the null hypothesis for virtually every empirical study that seeks to document the prevalence and impact of financial frictions. 


\section{Appendix A Static Nash equilibrium}

A static Nash equilibrium $\left(p_{1}^{N}(\omega), p_{2}^{N}(\omega)\right)$ in state $\omega$ is a solution to the system of equations

$$
\begin{aligned}
& \frac{\partial \pi_{1}\left(\omega, p_{1}^{N}(\omega), p_{2}^{N}(\omega)\right)}{\partial p_{1}}=0 \Longrightarrow\left(\exp \left(\frac{g(\omega)-\alpha\left(p_{1}^{N}(\omega)-p_{2}^{N}(\omega)\right)}{\nu}\right)+1\right) \frac{\nu}{\alpha}-p_{1}^{N}(\omega)+c=0 \\
& \frac{\partial \pi_{2}\left(\omega, p_{1}^{N}(\omega), p_{2}^{N}(\omega)\right)}{\partial p_{2}}=0 \Longrightarrow\left(\exp \left(\frac{g(-\omega)+\alpha\left(p_{1}^{N}(\omega)-p_{2}^{N}(\omega)\right)}{\nu}\right)+1\right) \frac{\nu}{\alpha}-p_{2}^{N}(\omega)+c=0 .
\end{aligned}
$$

The Jacobian of this system is

$$
\left(\begin{array}{cc}
-\left(\exp \left(\frac{g(\omega)-\alpha\left(p_{1}^{N}(\omega)-p_{2}^{N}(\omega)\right)}{\nu}\right)+1\right) & \exp \left(\frac{g(\omega)-\alpha\left(p_{1}^{N}(\omega)-p_{2}^{N}(\omega)\right)}{\nu}\right) \\
\exp \left(\frac{g(-\omega)+\alpha\left(p_{1}^{N}(\omega)-p_{2}^{N}(\omega)\right)}{\nu}\right) & -\left(\exp \left(\frac{g(-\omega)+\alpha\left(p_{1}^{N}(\omega)-p_{2}^{N}(\omega)\right)}{\nu}\right)+1\right)
\end{array}\right) .
$$

Standard arguments ensure the existence (Fudenberg \& Tirole 1991, Theorem 1.2) and uniqueness (Gale \& Nikaido 1965, Theorem 6) of a static Nash equilibrium.

The following proposition implies that we can normalize $\alpha=1$ and $c=0$ without loss of generality:

Proposition 1 Let $\left(p_{1}^{\circ}(\omega), p_{2}^{\circ}(\omega)\right)$ be a static Nash equilibrium in state $\omega$ for market size $M=1$, price sensitivity $\alpha=1$, and marginal cost $c=0$ and $\pi_{i}^{\circ}\left(\omega, p_{1}^{\circ}(\omega), p_{2}^{\circ}(\omega)\right)$ the associated profit of firm $i$. Then $\left(p_{1}^{N}(\omega)=\frac{1}{\alpha} p_{1}^{\circ}(\omega)+c, p_{2}^{N}(\omega)=\frac{1}{\alpha} p_{2}^{\circ}(\omega)+c\right)$ is a static Nash equilibrium in state $\omega$ for market size $M>0$, price sensitivity $\alpha>0$, and marginal cost $c \geq 0$ and the associated profit of firm $i$ is $\pi_{i}\left(\omega, p_{1}^{N}(\omega), p_{2}^{N}(\omega)\right)=$ $\frac{M}{\alpha} \pi_{i}^{\circ}\left(\omega, p_{1}^{\circ}(\omega), p_{2}^{\circ}(\omega)\right)$.

Proof. Plug $\left(p_{1}^{N}(\omega), p_{2}^{N}(\omega)\right)$ into equations A1 and $\mathrm{A} 2$ that define a static Nash equilibrium in state $\omega$ and simplify. Then plug into equations (4) and (5).

As a corollary, note that since $g(0)=0$, we have $p_{i}^{\circ}(0)=2 \nu$ and $\pi_{i}^{\circ}\left(0, p_{1}^{\circ}(0), p_{2}^{\circ}(0)\right)=$ $\nu$ in a static Nash equilibrium in state $\omega=0$.

\section{Appendix B Properties of the normal distribution}

Let $\phi(z)$ and $\Phi(z)$ be the standard normal probability density and cumulative distribution functions, respectively. Then we have that

$$
\Psi\left(\theta_{i}\right)=\Phi\left(\frac{\theta_{i}}{\sigma}\right), \quad \psi\left(\theta_{i}\right)=\frac{1}{\sigma} \phi\left(\frac{\theta_{i}}{\sigma}\right), \quad \psi^{\prime}\left(\theta_{i}\right)=-\frac{\theta_{i}}{\sigma^{3}} \phi\left(\frac{\theta_{i}}{\sigma}\right)
$$

and

$$
\Psi^{-1}(p)=\sigma \Phi^{-1}(p)
$$


In addition

$$
\Upsilon(\bar{\theta})=\int_{-\infty}^{\bar{\theta}} \theta_{i} d \Psi\left(\theta_{i}\right)=-\sigma \phi\left(\frac{\bar{\theta}}{\sigma}\right)
$$

\section{Appendix C Comparative statics}

Defining

$$
\begin{array}{lll}
A_{1}=\beta\left[V_{1}\left(\omega^{+}\right)-V_{1}(\omega)\right], & B_{1}=\beta\left[V_{1}(\omega)-V_{1}\left(\omega^{-}\right)\right], & Z_{1}=-F\left(\pi_{1}\right)+A_{1}+\left(B_{1}-A_{1}\right) x_{2}(\omega), \\
A_{2}=\beta\left[V_{2}\left(\omega^{-}\right)-V_{2}(\omega)\right], & B_{2}=\beta\left[V_{2}(\omega)-V_{2}\left(\omega^{+}\right)\right], & Z_{2}=-F\left(\pi_{2}\right)+A_{2}+\left(B_{2}-A_{2}\right) x_{1}(\omega),
\end{array}
$$

the system of equations given by equation (8) and its analog for firm 2 is

$$
\begin{aligned}
& x_{1}(\omega)=\Psi\left(Z_{1}\right), \\
& x_{2}(\omega)=\Psi\left(Z_{2}\right) .
\end{aligned}
$$

where we use the shorthand $\pi_{i}=\pi_{i}\left(\omega, p_{1}(\omega), p_{2}(\omega)\right)$.

First order. To obtain the first-order comparative statics $\frac{\partial x_{i}(\omega)}{\partial \pi_{j}}$, we first differentiate equations (A3) and (A4) with respect to $\pi_{1}$ to obtain

$$
\begin{gathered}
\frac{\partial x_{1}(\omega)}{\partial \pi_{1}}=\psi\left(Z_{1}\right)\left(-F^{\prime}\left(\pi_{1}\right)+\left(B_{1}-A_{1}\right) \frac{\partial x_{2}(\omega)}{\partial \pi_{1}}\right), \\
\frac{\partial x_{2}(\omega)}{\partial \pi_{1}}=\psi\left(Z_{2}\right)\left(B_{2}-A_{2}\right) \frac{\partial x_{1}(\omega)}{\partial \pi_{1}} .
\end{gathered}
$$

Solving yields

$$
\begin{gathered}
\frac{\partial x_{1}(\omega)}{\partial \pi_{1}}=\frac{1}{Y}\left\{-\psi\left(Z_{1}\right) F^{\prime}\left(\pi_{1}\right)\right\} \\
\frac{\partial x_{2}(\omega)}{\partial \pi_{1}}=\frac{1}{Y}\left\{-\psi\left(Z_{1}\right) \psi\left(Z_{2}\right) F^{\prime}\left(\pi_{1}\right)\left(B_{2}-A_{2}\right)\right\}
\end{gathered}
$$

where

$$
Y=1-\psi\left(Z_{1}\right) \psi\left(Z_{2}\right)\left(B_{1}-A_{1}\right)\left(B_{2}-A_{2}\right)
$$

Next, we differentiate equations (A3) and $(\mathrm{A} 4)$ with respect to $\pi_{2}$ to obtain

$$
\begin{gathered}
\frac{\partial x_{1}(\omega)}{\partial \pi_{2}}=\psi\left(Z_{1}\right)\left(B_{1}-A_{1}\right) \frac{\partial x_{2}(\omega)}{\partial \pi_{2}} \\
\frac{\partial x_{2}(\omega)}{\partial \pi_{2}}=\psi\left(Z_{2}\right)\left(-F^{\prime}\left(\pi_{2}\right)+\left(B_{2}-A_{2}\right) \frac{\partial x_{1}(\omega)}{\partial \pi_{2}}\right) .
\end{gathered}
$$


Solving yields

$$
\begin{gathered}
\frac{\partial x_{1}(\omega)}{\partial \pi_{2}}=\frac{1}{Y}\left\{-\psi\left(Z_{1}\right) \psi\left(Z_{2}\right) F^{\prime}\left(\pi_{2}\right)\left(B_{1}-A_{1}\right)\right\} \\
\frac{\partial x_{2}(\omega)}{\partial \pi_{2}}=\frac{1}{Y}\left\{-\psi\left(Z_{2}\right) F^{\prime}\left(\pi_{2}\right)\right\} .
\end{gathered}
$$

It is in general not possible to sign the first-order comparative statics $\frac{\partial x_{i}(\omega)}{\partial \pi_{j}}$. Note that absent financial frictions $(\zeta=0), F^{\prime}\left(\pi_{i}\right)=0$ and thus $\frac{\partial x_{i}(\omega)}{\partial \pi_{j}}=0$.

Second order. To obtain the second-order comparative statics $\frac{\partial^{2} x_{i}(\omega)}{\partial \pi_{j} \partial \pi_{k}}$, we first differentiate equations (A5) and (A6) with respect to $\pi_{1}$ and solve to obtain

$$
\begin{aligned}
& \frac{\partial^{2} x_{1}(\omega)}{\partial \pi_{1}^{2}}=\frac{1}{Y}\left\{-W_{1}-W_{2} \psi\left(Z_{1}\right)\left(B_{1}-A_{1}\right)\right\}, \\
& \frac{\partial^{2} x_{2}(\omega)}{\partial \pi_{1}^{2}}=\frac{1}{Y}\left\{-W_{2}-W_{1} \psi\left(Z_{2}\right)\left(B_{2}-A_{2}\right)\right\},
\end{aligned}
$$

where

$$
\begin{gathered}
W_{1}=-\psi^{\prime}\left(Z_{1}\right)\left(-F^{\prime}\left(\pi_{1}\right)+\left(B_{1}-A_{1}\right) \frac{\partial x_{2}(\omega)}{\partial \pi_{1}}\right)^{2}+\psi\left(Z_{1}\right) F^{\prime \prime}\left(\pi_{1}\right), \\
W_{2}=-\psi^{\prime}\left(Z_{2}\right)\left(\left(B_{2}-A_{2}\right) \frac{\partial x_{1}(\omega)}{\partial \pi_{1}}\right)^{2} .
\end{gathered}
$$

Next, we differentiate equations (A5) and (A6) with respect to $\pi_{2}$ and solve to obtain

$$
\begin{aligned}
& \frac{\partial^{2} x_{1}(\omega)}{\partial \pi_{1} \partial \pi_{2}}=\frac{1}{Y}\left\{-W_{3}-W_{4} \psi\left(Z_{1}\right)\left(B_{1}-A_{1}\right)\right\}, \\
& \frac{\partial^{2} x_{2}(\omega)}{\partial \pi_{1} \partial \pi_{2}}=\frac{1}{Y}\left\{-W_{4}-W_{3} \psi\left(Z_{2}\right)\left(B_{2}-A_{2}\right)\right\},
\end{aligned}
$$

where

$$
\begin{aligned}
& W_{3}=-\psi^{\prime}\left(Z_{1}\right)\left(B_{1}-A_{1}\right) \frac{\partial x_{2}(\omega)}{\partial \pi_{2}}\left(-F^{\prime}\left(\pi_{1}\right)+\left(B_{1}-A_{1}\right) \frac{\partial x_{2}(\omega)}{\partial \pi_{1}}\right), \\
& W_{4}=-\psi^{\prime}\left(Z_{2}\right)\left(-F^{\prime}\left(\pi_{2}\right)+\left(B_{2}-A_{2}\right) \frac{\partial x_{1}(\omega)}{\partial \pi_{2}}\right)\left(B_{2}-A_{2}\right) \frac{\partial x_{1}(\omega)}{\partial \pi_{1}} .
\end{aligned}
$$

It is easy to show that $\frac{\partial^{2} x_{i}(\omega)}{\partial \pi_{1} \partial \pi_{2}}=\frac{\partial^{2} x_{i}(\omega)}{\partial \pi_{2} \partial \pi_{1}}$.

Finally, we differentiate equations $\mathrm{A} 9$ and $\mathrm{A} 10$ with respect to $\pi_{2}$ and solve to obtain

$$
\frac{\partial^{2} x_{1}(\omega)}{\partial \pi_{2}^{2}}=\frac{1}{Y}\left\{-W_{5}-W_{6} \psi\left(Z_{1}\right)\left(B_{1}-A_{1}\right)\right\}
$$




$$
\frac{\partial^{2} x_{2}(\omega)}{\partial \pi_{2}^{2}}=\frac{1}{Y}\left\{-W_{6}-W_{5} \psi\left(Z_{2}\right)\left(B_{2}-A_{2}\right)\right\}
$$

where

$$
\begin{gathered}
W_{5}=-\psi^{\prime}\left(Z_{1}\right)\left(\left(B_{1}-A_{1}\right) \frac{\partial x_{2}(\omega)}{\partial \pi_{2}}\right)^{2} \\
W_{6}=-\psi^{\prime}\left(Z_{2}\right)\left(-F^{\prime}\left(\pi_{2}\right)+\left(B_{2}-A_{2}\right) \frac{\partial x_{1}(\omega)}{\partial \pi_{2}}\right)^{2}+\psi\left(Z_{2}\right) F^{\prime \prime}\left(\pi_{2}\right) .
\end{gathered}
$$

\section{Appendix D System of equations for symmetric equi- librium}

A symmetric equilibrium is a solution to the system of equations

$$
\mathcal{H}(\mathcal{X})=0,
$$

where

$$
\mathcal{X}=\left(V_{1}(-L), \ldots, V_{1}(L), U_{1}(-L), \ldots, U_{1}(L), p_{1}(-L), \ldots, p_{1}(L), x_{1}(-L), \ldots, x_{1}(L)\right)
$$

is a vector of $8 L+4$ unknowns and $\mathcal{H}$ is defined by the following $8 L+4$ equations:

$$
\begin{gathered}
-V_{1}(\omega)+\pi_{1}\left(\omega, p_{1}(\omega), p_{2}(\omega)\right)+U_{1}(\omega)=0, \quad \omega \in\{-L, \ldots, L\}, \quad \text { (A19) } \\
-U_{1}(\omega)-F\left(\pi_{1}\left(\omega, p_{1}(\omega), p_{2}(\omega)\right) x_{1}(\omega)-\int_{-\infty}^{Z_{1}} \theta_{1} d \Psi\left(\theta_{1}\right)+\beta\left[V_{1}\left(\omega^{+}\right) x_{1}(\omega)\left(1-x_{2}(\omega)\right)\right.\right. \\
\left.+V_{1}(\omega)\left(1-x_{1}(\omega)-x_{2}(\omega)+2 x_{1}(\omega) x_{2}(\omega)\right)+V_{1}\left(\omega^{-}\right)\left(1-x_{1}(\omega)\right) x_{2}(\omega)\right] \\
=0, \quad \omega \in\{-L, \ldots, L\}, \\
\frac{\partial \pi_{1}\left(\omega, p_{1}(\omega), p_{2}(\omega)\right)}{\partial p_{1}}\left(1-F^{\prime}\left(\pi_{1}\left(\omega, p_{1}(\omega), p_{2}(\omega)\right)\right) x_{1}(\omega)+\frac{\partial U_{1}(\omega)}{\partial x_{2}} \frac{\partial x_{2}(\omega)}{\partial \pi_{1}}\right) \\
+\frac{\partial \pi_{2}\left(\omega, p_{1}(\omega), p_{2}(\omega)\right)}{\partial p_{1}} \frac{\partial U_{1}(\omega)}{\partial x_{2}} \frac{\partial x_{2}(\omega)}{\partial \pi_{2}}=0, \quad \omega \in\{-L, \ldots, L\}, \quad \text { (A21) } \\
-x_{1}(\omega)+\Psi\left(Z_{1}\right)=0, \quad \omega \in\{-L, \ldots, L\},
\end{gathered}
$$

where

$$
\frac{\partial U_{1}(\omega)}{\partial x_{2}}=-B_{1}+\left(B_{1}-A_{1}\right) x_{1}(\omega)
$$

$\frac{\partial x_{2}(\omega)}{\partial \pi_{j}}$ is given in equations $\mathrm{A} 8$ and $\sqrt{\mathrm{A} 12}$, and we continue to use the shorthands $A_{i}, B_{i}, Z_{i}$, and $Y$ defined in Appendix C. Throughout it is understood that we use the shorthands

$$
V_{2}(\omega)=V_{1}(-\omega), \quad U_{2}(\omega)=U_{1}(-\omega), \quad p_{2}(\omega)=p_{1}(-\omega), \quad x_{2}(\omega)=x_{1}(-\omega) .
$$


Note that we substituted equation 8 into $\int_{-\infty}^{\Psi^{-1}\left(x_{1}(\omega)\right)} \theta_{1} d \Psi\left(\theta_{1}\right)$ in equation 9 to obtain equation A20. This substitution avoids numerical issues that arise because our assumption $\theta_{i} \sim N\left(0, \sigma^{2}\right)$ implies $\lim _{p \rightarrow 0+} \Psi^{-1}(p)=-\infty$ and $\lim _{p \rightarrow 1-} \Psi^{-1}(p)=\infty$ and because $\Psi^{-1}(-\epsilon)$ and $\Psi^{-1}(1+\epsilon)$ are undefined for all $\epsilon>0$.

To simplify the notation, and without loss of generality, we redefine the parameters $\alpha$ and $g(\omega)$ to be $\frac{\alpha}{\nu}$ and $\frac{g(\omega)}{\nu}$. This avoids having to carry along $\nu$. Using this notation, we have

$$
\begin{gathered}
\frac{\partial \pi_{1}\left(\omega, p_{1}(\omega), p_{2}(\omega)\right)}{\partial p_{1}}=\frac{M\left(1+\left(1-\left(p_{1}(\omega)-c\right) \alpha\right) \exp \left(-g(\omega)+\alpha\left(p_{1}(\omega)-p_{2}(\omega)\right)\right)\right)}{\left(1+\exp \left(-g(\omega)+\alpha\left(p_{1}(\omega)-p_{2}(\omega)\right)\right)\right)^{2}} \\
\frac{\partial \pi_{2}\left(\omega, p_{1}(\omega), p_{2}(\omega)\right)}{\partial p_{1}}=\frac{M\left(p_{2}(\omega)-c\right) \alpha \exp \left(-g(-\omega)-\alpha\left(p_{1}(\omega)-p_{2}(\omega)\right)\right)}{\left(1+\exp \left(-g(-\omega)-\alpha\left(p_{1}(\omega)-p_{2}(\omega)\right)\right)\right)^{2}}
\end{gathered}
$$

To facilitate solving the system of equations and avoid asymptotes, we multiply equation (A21) by

$$
\frac{\left(1+\exp \left(-g(\omega)+\alpha\left(p_{1}(\omega)-p_{2}(\omega)\right)\right)\right)^{2}}{M \alpha \exp \left(-g(\omega)+\alpha\left(p_{1}(\omega)-p_{2}(\omega)\right)\right)} .
$$

The Jacobian of the system of equations A19-A22 is available from the authors upon request.

\section{Appendix E Checking for equilibria}

To check that a solution to the system of equations A19-A22 is an equilibrium, we check that there is no profitable unilateral deviation. Recall that, in the pricing stage, firm 1 anticipates that changing its price changes its investment as well as the investment of firm 2 in the investment stage. We proceed in two steps.

\section{Appendix E.1 Local deviations}

First, we examine local deviations. Without imposing $\frac{\partial U_{1}(\omega)}{\partial x_{1}}=0$ from the envelope theorem, equation (11) reads

$$
\begin{gathered}
\frac{\partial \pi_{1}\left(\omega, p_{1}(\omega), p_{2}(\omega)\right)}{\partial p_{1}}\left(1-F^{\prime}\left(\pi_{1}\left(\omega, p_{1}(\omega), p_{2}(\omega)\right)\right) x_{1}(\omega)+\frac{\partial U_{1}(\omega)}{\partial x_{1}} \frac{\partial x_{1}(\omega)}{\partial \pi_{1}}+\frac{\partial U_{1}(\omega)}{\partial x_{2}} \frac{\partial x_{2}(\omega)}{\partial \pi_{1}}\right) \\
+\frac{\partial \pi_{2}\left(\omega, p_{1}(\omega), p_{2}(\omega)\right)}{\partial p_{1}}\left(\frac{\partial U_{1}(\omega)}{\partial x_{1}} \frac{\partial x_{1}(\omega)}{\partial \pi_{2}}+\frac{\partial U_{1}(\omega)}{\partial x_{2}} \frac{\partial x_{2}(\omega)}{\partial \pi_{2}}\right)=0, \quad(\mathrm{~A} 24)
\end{gathered}
$$

where $\frac{\partial U_{1}(\omega)}{\partial x_{2}}$ is given in equation $\mathrm{A} 23, \frac{\partial x_{1}(\omega)}{\partial \pi_{j}}$ in equations $\left.\mathrm{A} 7\right)$ and $(\mathrm{A} 8)$, and we continue to use the shorthands $A_{i}, B_{i}, Z_{i}$, and $Y$ defined in Appendix C (with $\pi_{i}=$ $\left.\pi_{i}\left(\omega, p_{1}(\omega), p_{2}(\omega)\right)\right)$. Direct calculation using Leibniz's rule yields

$$
\frac{\partial U_{1}(\omega)}{\partial x_{1}}=-F\left(\pi_{1}\left(\omega, p_{1}(\omega), p_{2}(\omega)\right)\right)-\Psi^{-1}\left(x_{1}(\omega)\right)+A_{1}+\left(B_{1}-A_{1}\right) x_{2}(\omega) .
$$


Restricting attention to local deviations, we examine the derivative of the left-hand side equation A24 with respect to $p_{1}(\omega)$ :

$$
\begin{aligned}
& \frac{\partial^{2} \pi_{1}\left(\omega, p_{1}(\omega), p_{2}(\omega)\right)}{\partial p_{1}^{2}}\left(1-F^{\prime}\left(\pi_{1}\left(\omega, p_{1}(\omega), p_{2}(\omega)\right)\right) x_{1}(\omega)+\frac{\partial U_{1}(\omega)}{\partial x_{1}} \frac{\partial x_{1}(\omega)}{\partial \pi_{1}}+\frac{\partial U_{1}(\omega)}{\partial x_{2}} \frac{\partial x_{2}(\omega)}{\partial \pi_{1}}\right) \\
& +\frac{\partial \pi_{1}\left(\omega, p_{1}(\omega), p_{2}(\omega)\right)}{\partial p_{1}}\left[-F^{\prime \prime}\left(\pi_{1}\left(\omega, p_{1}(\omega), p_{2}(\omega)\right)\right) \frac{\partial \pi_{1}\left(\omega, p_{1}(\omega), p_{2}(\omega)\right)}{\partial p_{1}} x_{1}(\omega)\right. \\
& -F^{\prime}\left(\pi_{1}\left(\omega, p_{1}(\omega), p_{2}(\omega)\right)\right)\left(\frac{\partial x_{1}(\omega)}{\partial \pi_{1}} \frac{\partial \pi_{1}\left(\omega, p_{1}(\omega), p_{2}(\omega)\right)}{\partial p_{1}}+\frac{\partial x_{1}(\omega)}{\partial \pi_{2}} \frac{\partial \pi_{2}\left(\omega, p_{1}(\omega), p_{2}(\omega)\right)}{\partial p_{1}}\right) \\
& -F^{\prime}\left(\pi_{1}\left(\omega, p_{1}(\omega), p_{2}(\omega)\right)\right) \frac{\partial \pi_{1}\left(\omega, p_{1}(\omega), p_{2}(\omega)\right)}{\partial p_{1}} \frac{\partial x_{1}(\omega)}{\partial \pi_{1}} \\
& +\frac{\partial^{2} U_{1}(\omega)}{\partial x_{1}^{2}}\left(\frac{\partial x_{1}(\omega)}{\partial \pi_{1}} \frac{\partial \pi_{1}\left(\omega, p_{1}(\omega), p_{2}(\omega)\right)}{\partial p_{1}}+\frac{\partial x_{1}(\omega)}{\partial \pi_{2}} \frac{\partial \pi_{2}\left(\omega, p_{1}(\omega), p_{2}(\omega)\right)}{\partial p_{1}}\right) \frac{\partial x_{1}(\omega)}{\partial \pi_{1}} \\
& +\frac{\partial^{2} U_{1}(\omega)}{\partial x_{1} \partial x_{2}}\left(\frac{\partial x_{2}(\omega)}{\partial \pi_{1}} \frac{\partial \pi_{1}\left(\omega, p_{1}(\omega), p_{2}(\omega)\right)}{\partial p_{1}}+\frac{\partial x_{2}(\omega)}{\partial \pi_{2}} \frac{\partial \pi_{2}\left(\omega, p_{1}(\omega), p_{2}(\omega)\right)}{\partial p_{1}}\right) \frac{\partial x_{1}(\omega)}{\partial \pi_{1}} \\
& +\frac{\partial U_{1}(\omega)}{\partial x_{1}}\left(\frac{\partial^{2} x_{1}(\omega)}{\partial \pi_{1}^{2}} \frac{\partial \pi_{1}\left(\omega, p_{1}(\omega), p_{2}(\omega)\right)}{\partial p_{1}}+\frac{\partial^{2} x_{1}(\omega)}{\partial \pi_{1} \partial \pi_{2}} \frac{\partial \pi_{2}\left(\omega, p_{1}(\omega), p_{2}(\omega)\right)}{\partial p_{1}}\right) \\
& +\frac{\partial^{2} U_{1}(\omega)}{\partial x_{2} \partial x_{1}}\left(\frac{\partial x_{1}(\omega)}{\partial \pi_{1}} \frac{\partial \pi_{1}\left(\omega, p_{1}(\omega), p_{2}(\omega)\right)}{\partial p_{1}}+\frac{\partial x_{1}(\omega)}{\partial \pi_{2}} \frac{\partial \pi_{2}\left(\omega, p_{1}(\omega), p_{2}(\omega)\right)}{\partial p_{1}}\right) \frac{\partial x_{2}(\omega)}{\partial \pi_{1}} \\
& \left.+\frac{\partial U_{1}(\omega)}{\partial x_{2}}\left(\frac{\partial^{2} x_{2}(\omega)}{\partial \pi_{1}^{2}} \frac{\partial \pi_{1}\left(\omega, p_{1}(\omega), p_{2}(\omega)\right)}{\partial p_{1}}+\frac{\partial^{2} x_{2}(\omega)}{\partial \pi_{1} \partial \pi_{2}} \frac{\partial \pi_{2}\left(\omega, p_{1}(\omega), p_{2}(\omega)\right)}{\partial p_{1}}\right)\right] \\
& +\frac{\partial^{2} \pi_{2}\left(\omega, p_{1}(\omega), p_{2}(\omega)\right)}{\partial p_{1}^{2}}\left(\frac{\partial U_{1}(\omega)}{\partial x_{1}} \frac{\partial x_{1}(\omega)}{\partial \pi_{2}}+\frac{\partial U_{1}(\omega)}{\partial x_{2}} \frac{\partial x_{2}(\omega)}{\partial \pi_{2}}\right) \\
& +\frac{\partial \pi_{2}\left(\omega, p_{1}(\omega), p_{2}(\omega)\right)}{\partial p_{1}}\left[-F^{\prime}\left(\pi_{1}\left(\omega, p_{1}(\omega), p_{2}(\omega)\right)\right) \frac{\partial \pi_{1}\left(\omega, p_{1}(\omega), p_{2}(\omega)\right)}{\partial p_{1}} \frac{\partial x_{1}(\omega)}{\partial \pi_{2}}\right. \\
& +\frac{\partial^{2} U_{1}(\omega)}{\partial x_{1}^{2}}\left(\frac{\partial x_{1}(\omega)}{\partial \pi_{1}} \frac{\partial \pi_{1}\left(\omega, p_{1}(\omega), p_{2}(\omega)\right)}{\partial p_{1}}+\frac{\partial x_{1}(\omega)}{\partial \pi_{2}} \frac{\partial \pi_{2}\left(\omega, p_{1}(\omega), p_{2}(\omega)\right)}{\partial p_{1}}\right) \frac{\partial x_{1}(\omega)}{\partial \pi_{2}} \\
& +\frac{\partial^{2} U_{1}(\omega)}{\partial x_{1} \partial x_{2}}\left(\frac{\partial x_{2}(\omega)}{\partial \pi_{1}} \frac{\partial \pi_{1}\left(\omega, p_{1}(\omega), p_{2}(\omega)\right)}{\partial p_{1}}+\frac{\partial x_{2}(\omega)}{\partial \pi_{2}} \frac{\partial \pi_{2}\left(\omega, p_{1}(\omega), p_{2}(\omega)\right)}{\partial p_{1}}\right) \frac{\partial x_{1}(\omega)}{\partial \pi_{2}} \\
& +\frac{\partial U_{1}(\omega)}{\partial x_{1}}\left(\frac{\partial^{2} x_{1}(\omega)}{\partial \pi_{2}^{2}} \frac{\partial \pi_{2}\left(\omega, p_{1}(\omega), p_{2}(\omega)\right)}{\partial p_{1}}+\frac{\partial^{2} x_{1}(\omega)}{\partial \pi_{2} \partial \pi_{1}} \frac{\partial \pi_{1}\left(\omega, p_{1}(\omega), p_{2}(\omega)\right)}{\partial p_{1}}\right) \\
& +\frac{\partial^{2} U_{1}(\omega)}{\partial x_{2} \partial x_{1}}\left(\frac{\partial x_{1}(\omega)}{\partial \pi_{1}} \frac{\partial \pi_{1}\left(\omega, p_{1}(\omega), p_{2}(\omega)\right)}{\partial p_{1}}+\frac{\partial x_{1}(\omega)}{\partial \pi_{2}} \frac{\partial \pi_{2}\left(\omega, p_{1}(\omega), p_{2}(\omega)\right)}{\partial p_{1}}\right) \frac{\partial x_{2}(\omega)}{\partial \pi_{2}} \\
& \left.+\frac{\partial U_{1}(\omega)}{\partial x_{2}}\left(\frac{\partial^{2} x_{2}(\omega)}{\partial \pi_{2}^{2}} \frac{\partial \pi_{2}\left(\omega, p_{1}(\omega), p_{2}(\omega)\right)}{\partial p_{1}}+\frac{\partial^{2} x_{2}(\omega)}{\partial \pi_{2} \partial \pi_{1}} \frac{\partial \pi_{1}\left(\omega, p_{1}(\omega), p_{2}(\omega)\right)}{\partial p_{1}}\right)\right],
\end{aligned}
$$

where $\frac{\partial^{2} x_{1}(\omega)}{\partial \pi_{j} \partial \pi_{k}}$ is given in equations A13 A18, and

$$
\frac{\partial^{2} U_{1}(\omega)}{\partial x_{1}^{2}}=-\frac{1}{\psi\left(\Psi^{-1}\left(x_{1}(\omega)\right)\right)},
$$




$$
\begin{gathered}
\frac{\partial^{2} U_{1}(\omega)}{\partial x_{1} \partial x_{2}}=\frac{\partial^{2} U_{1}(\omega)}{\partial x_{2} \partial x_{1}}=B_{1}-A_{1}, \\
\frac{\partial^{2} \pi_{1}\left(\omega, p_{1}(\omega), p_{2}(\omega)\right)}{\partial p_{1}^{2}}=-\frac{1}{\left(1+\exp \left(-g(\omega)+\alpha\left(p_{1}(\omega)-p_{2}(\omega)\right)\right)\right)^{3}} \\
\cdot\left\{M \alpha \exp \left(-g(\omega)+\alpha\left(p_{1}(\omega)-p_{2}(\omega)\right)\right)\right. \\
\cdot\left(2\left(1+\exp \left(-g(\omega)+\alpha\left(p_{1}(\omega)-p_{2}(\omega)\right)\right)+\left(p_{1}(\omega)-c\right) \alpha\left(1-\exp \left(-g(\omega)+\alpha\left(p_{1}(\omega)-p_{2}(\omega)\right)\right)\right)\right)\right\}, \\
\frac{\partial^{2} \pi_{2}\left(\omega, p_{1}(\omega), p_{2}(\omega)\right)}{\partial p_{1}^{2}}=-\frac{1}{\left(1+\exp \left(-g(-\omega)-\alpha\left(p_{1}(\omega)-p_{2}(\omega)\right)\right)\right)^{3}} \\
\cdot\left\{M \alpha^{2} \exp \left(-g(-\omega)-\alpha\left(p_{1}(\omega)-p_{2}(\omega)\right)\right)\left(p_{2}(\omega)-c\right)\left(1-\exp \left(-g(-\omega)-\alpha\left(p_{1}(\omega)-p_{2}(\omega)\right)\right)\right)\right\} .
\end{gathered}
$$

Firm 1 has a profitable unilateral local deviation in state $\omega$ if the derivative in equation A25 evaluated at the candidate solution is positive. In this case, the candidate solution is not an equilibrium.

\section{Appendix E.2 Global deviations}

Second, we examine global deviations by solving the saddle point problem

$$
\begin{array}{r}
\max _{p_{1}} \min _{x_{1}, x_{2}} \pi_{1}\left(\omega, p_{1}, p_{2}(\omega)\right)-F\left(\pi_{1}\left(\omega, p_{1}, p_{2}(\omega)\right)\right) x_{1}-\int_{-\infty}^{\Psi^{-1}\left(x_{1}\right)} \theta_{1} d \Psi\left(\theta_{1}\right) \\
+\beta\left[V_{1}\left(\omega^{+}\right) x_{1}\left(1-x_{2}\right)+V_{1}(\omega)\left(1-x_{1}-x_{2}+2 x_{1} x_{2}\right)+V_{1}\left(\omega^{-}\right)\left(1-x_{1}\right) x_{2}\right]
\end{array}
$$

subject to equation (8) and its analog for firm 2 (with $x_{1}(\omega)$ and $x_{2}(\omega)$ replaced by $x_{1}$ and $x_{2}$ ). In the spirit of simple penal codes (Abreu 1988), we assume that after deviating in the pricing stage firm 1 faces the worst possible continuation in the investment stage. This allows the model to generate the widest set of possible equilibrium behaviors.

Accounting for numerical precision, we say that firm 1 has a profitable unilateral global deviation in state $\omega$ if the value of the saddle point problem in equation (A26) is larger than the value of the objective function evaluated at the candidate solution and if $p_{1}, x_{1}$, and $x_{2}$ in the saddle point problem are sufficiently different from the candidate solution. In this case, the candidate solution is not an equilibrium.

To solve the saddle point problem, we nest the inner minimization problem given $p_{1}$ into the outer maximization problem over $p_{1}$. Starting with the inner minimization problem given $p_{1}$, we substitute the analog of equation (8) for firm 2 into equation (8) and aim to obtain all solutions to the resulting univariate equation in $x_{1}$ by a combination of a grid search and a derivative-free bisection algorithm. We select the solution that is associated with the worst possible continuation for firm 1 . Turning to the outer maximization problem over $p_{1}$, we use a derivative-free golden section search algorithm.

Note that the existence of a profitable unilateral local deviation does not imply the existence of a profitable unilateral global deviation. This is because in equation A25 
we perturb the continuation in the investment stage around the candidate solution via the second-order comparative statics $\frac{\partial^{2} x_{i}(\omega)}{\partial \pi_{j} \partial \pi_{j}}$ whereas in the saddle point problem in equation (A26) we condition on the worst possible continuation in the investment stage.

\section{Appendix F Limiting distribution}

Let $P$ denote the $(2 L+1) \times(2 L+1)$ state-to-state transition probability matrix constructed in equation 12 with typical element $P_{\omega, \omega^{\prime}}$. The assumption $\theta_{i} \sim N\left(0, \sigma^{2}\right)$ ensures $x_{i}(\omega) \in(0,1)$ and thus $P_{\omega, \omega-1}>0, P_{\omega, \omega}<1$, and $P_{\omega, \omega+1}>0$. It follows that the entire state space is one closed communicating class. The $1 \times(2 L+1)$ limiting distribution $\mu^{\infty}$ is a solution to the system of linear equations

$$
\mu^{\infty} P=\mu^{\infty} \Longleftrightarrow \mu^{\infty}(P-I)=0,
$$

where $I$ is the $(2 L+1) \times(2 L+1)$ identity matrix and 0 is a $1 \times(2 L+1)$ vector of zeros. Because the system of linear equations is homogenous, if $\mu^{\infty}$ is a solution, then so is $\alpha \mu^{\infty}$ for any $\alpha \in \mathbb{R}$. We are therefore free to fix the scale of $\mu^{\infty}$ (or normalize any solution after obtaining it).

We develop a recursive formula for computing $\mu^{\infty}$. To reduce the number of unknowns and equations, we exploit that $P$ is symmetric in the sense that $P_{-\omega,-\omega^{\prime}}=$ $P_{\omega, \omega^{\prime}}$ for all $\omega, \omega^{\prime} \in\{0,1, \ldots, L\}$. We thus have

$$
\begin{aligned}
& \left(\begin{array}{lllllll}
\mu^{\infty}(0) & \mu^{\infty}(1) & \ldots & \mu^{\infty}(\omega) & \ldots & \mu^{\infty}(L-1) & \mu^{\infty}(L)
\end{array}\right) \\
& \left(\begin{array}{ccccccc}
P_{0,0}-1 & P_{0,1} & 0 & 0 & 0 & \cdots & 0 \\
2 P_{1,0} & P_{1,1}-1 & P_{1,2} & 0 & 0 & \cdots & 0 \\
0 & P_{2,1} & P_{2,2}-1 & P_{2,3} & 0 & \cdots & 0 \\
0 & \cdots & \ddots & \ddots & \ddots & \cdots & 0 \\
0 & \cdots & P_{\omega, \omega-1} & P_{\omega, \omega}-1 & P_{\omega, \omega+1} & \cdots & 0 \\
0 & \cdots & \ddots & \ddots & \ddots & \cdots & 0 \\
0 & \cdots & 0 & P_{L-2, L-3} & P_{L-2, L-2}-1 & P_{L-2, L-1} & 0 \\
0 & \cdots & 0 & 0 & P_{L-1, L-2} & P_{L-1, L-1}-1 & P_{L-1, L} \\
0 & \cdots & 0 & 0 & 0 & P_{L, L-1} & P_{L, L}-1
\end{array}\right)=0,
\end{aligned}
$$

where the multiplication of $P_{1,0}$ by 2 in the second row and first column is the necessary adjustment for the dropped equations. Using that each row of $P$ sums to 1 , this can be rewritten as

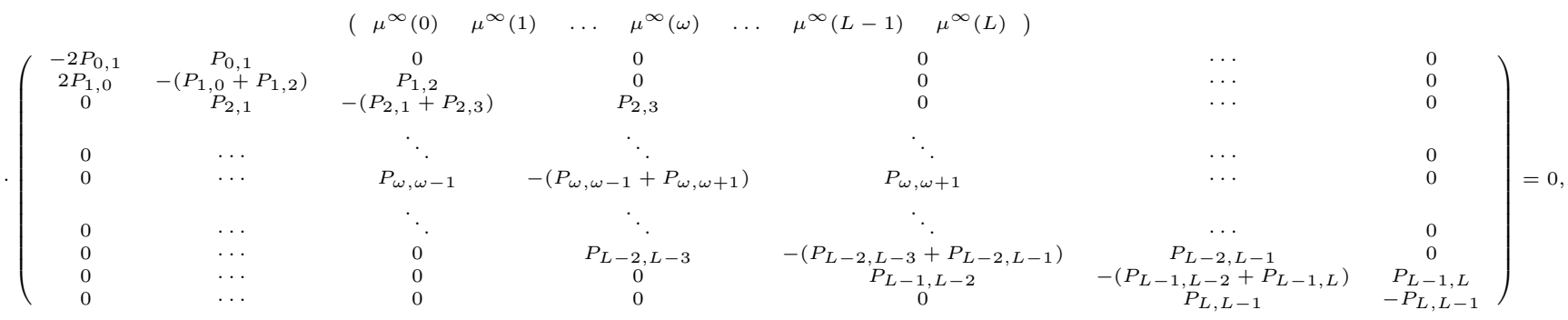


where the multiplication of $P_{0,1}$ by 2 in the first row and first column is the necessary adjustment for the dropped equations, or

$$
\begin{gathered}
-2 P_{0,1} \mu^{\infty}(0)+2 P_{1,0} \mu^{\infty}(1)=0, \\
P_{0,1} \mu^{\infty}(0)-\left(P_{1,0}+P_{1,2}\right) \mu^{\infty}(1)+P_{2,1} \mu^{\infty}(2)=0, \\
P_{1,2} \mu^{\infty}(1)-\left(P_{2,1}+P_{2,3}\right) \mu^{\infty}(2)+P_{3,2} \mu^{\infty}(3)=0, \\
\vdots \\
P_{\omega-1, \omega} \mu^{\infty}(\omega-1)-\left(P_{\omega, \omega-1}+P_{\omega, \omega+1}\right) \mu^{\infty}(\omega)+P_{\omega+1, \omega} \mu^{\infty}(\omega+1)=0, \\
\vdots \\
P_{L-3, L-2} \mu^{\infty}(L-3)-\left(P_{L-2, L-3}+P_{L-2, L-1}\right) \mu^{\infty}(L-2)+P_{L-1, L-2} \mu^{\infty}(L-1)=0, \\
P_{L-2, L-1} \mu^{\infty}(L-2)-\left(P_{L-1, L-2}+P_{L-1, L}\right) \mu^{\infty}(L-1)+P_{L, L-1} \mu^{\infty}(L)=0, \\
P_{L-1, L} \mu^{\infty}(L-1)-P_{L, L-1} \mu^{\infty}(L)=0 .
\end{gathered}
$$

Fixing $\mu^{\infty}(0)$, the first equation yields

$$
\mu^{\infty}(1)=\frac{P_{0,1}}{P_{1,0}} \mu^{\infty}(0)
$$

Plugging this into the second equation yields

$$
\mu^{\infty}(2)=\frac{P_{1,2} P_{0,1}}{P_{2,1} P_{1,0}} \mu^{\infty}(0)=\frac{P_{1,2}}{P_{2,1}} \mu^{\infty}(1) .
$$

Plugging this into the third equation yields

$$
\mu^{\infty}(3)=\frac{P_{2,3} P_{1,2} P_{0,1}}{P_{3,2} P_{2,1} P_{1,0}} \mu^{\infty}(0)=\frac{P_{2,3}}{P_{3,2}} \mu^{\infty}(2) .
$$

Continuing in this way yields the recursion

$$
\mu^{\infty}(\omega)=\frac{\prod_{i=1}^{\omega} P_{i-1, i}}{\prod_{i=1}^{\omega} P_{i, i-1}} \mu^{\infty}(0)=\frac{P_{\omega-1, \omega}}{P_{\omega, \omega-1}} \mu^{\infty}(\omega-1), \quad \omega \in\{1,2, \ldots, L\} .
$$

To account for numerical precision, we construct

$$
P_{\omega-1, \omega}=x_{1}(\omega-1)\left(1-x_{2}(\omega-1)\right), \quad P_{\omega, \omega-1}=\left(1-x_{1}(\omega)\right) x_{2}(\omega), \quad \omega \in\{1,2, \ldots, L\},
$$

by first evaluating the right-hand side of equation (8) and its analog for firm 2 using symbolic math with infinite precision arithmetic. We then execute the recursion using symbolic math to prevent over- and underflows. 


\section{References}

Abreu, D. (1988), 'On the theory of infinitely repeated games with discounting', Econometrica 56(2), 383-396.

Akcigit, U. \& Ates, S. (2020), Slowing business dynamism and productivity growth in the United States, Working paper, University of Chicago, Chicago.

Albuquerque, R. \& Hopenhayn, H. (2004), 'Optimal lending contracts and firm dynamics', Review of Economic Studies 71(2), 285-315.

Berry, S., Gaynor, M. \& Scott-Morton, F. (2020), 'Do increasing markups matter? Lessons from empirical industrial organization', Journal of Economic Perspectives $33(3), 44-68$.

Besanko, D., Doraszelski, U., Kryukov, Y. \& Satterthwaite, M. (2010), 'Learningby-doing, organizational forgetting, and industry dynamics', Econometrica 78(2), 453-508.

Bolton, P. \& Sharfstein, D. (1990), 'A theory of predation based on agency problems in financial contracting', American Economic Review 80(1), 93-106.

Borkovsky, R., Doraszelski, U. \& Kryukov, Y. (2010), 'A user's guide to solving dynamic stochastic games using the homotopy method', Operations Research 58(4), 1116-1132.

Borkovsky, R., Doraszelski, U. \& Kryukov, Y. (2012), 'A dynamic quality ladder model with entry and exit: Exploring the equilibrium correspondence using the homotopy method', Quantitative Marketing and Economics 10(2), 197-229.

Brander, J. \& Lewis, T. (1986), 'Oligopoly and financial structure: The limited liability effect', American Economic Review 76(5), 956-970.

Budd, C., Harris, C. \& Vickers, J. (1993), 'A model of the evolution of duopoly: Does the asymmetry between firms tend to increase or decrease?', Review of Economic Studies 60(3), 543-573.

Clementi, G. \& Hopenhayn, H. (2006), 'A theory of financing constraints and firm dynamics', Quarterly Journal of Economics 121(1), 229-265.

Cooley, T. \& Quadrini, V. (2001), 'Financial markets and firm dynamics', American Economic Review 91(5), 1286-1310.

Corbae, D. \& D'Erasmo, P. (2021), 'Capital buffers in a quantitative model of banking industry dynamics', Econometrica forthcoming. 
Doraszelski, U. \& Pakes, A. (2007), A framework for applied dynamic analysis in IO, in M. Armstrong \& R. Porter, eds, 'Handbook of Industrial Organization', Vol. 3, North-Holland, Amsterdam, pp. 1887-1966.

Doraszelski, U. \& Satterthwaite, M. (2010), 'Computable Markov-perfect industry dynamics', Rand Journal of Economics 41(2), 215-243.

Dou, W., Ji, Y. \& Wu, W. (2021), 'Competition, profitability, and risk premia', Journal of Financial Economics 140(2), 582-620.

Ericson, R. \& Pakes, A. (1995), 'Markov-perfect industry dynamics: A framework for empirical work', Review of Economic Studies 62(1), 53-82.

Fershtman, C. \& Judd, K. (1987), 'Equilibrium incentives in oligopoly', American Economic Review 77(5), 927-940.

Fudenberg, D. \& Tirole, J. (1991), Game theory, MIT Press, Cambridge.

Gale, D. \& Nikaido, H. (1965), 'The Jacobian matrix and global univalence of mappings', Mathematische Annalen 159, 81-93.

Giering, R., Kaminski, T. \& Slawig, T. (2005), 'Generating efficient derivative code with TAF: Adjoint and tangent linear Euler flow around an airfoil', Future Generation Computer Systems 21(8), 1345-1355.

Gomes, J. (2001), 'Financing investment', American Economic Review 91(5), 12631285 .

Hayashi, F. (1982), 'Tobin's marginal q and average q: A neoclassical interpretation', Econometrica 50(1), 213-224.

Hopenhayn, H. (1992), 'Entry, exit, and firm dynamics in long-run equilibrium', Econometrica 60(5), 1127-1150.

Liu, E., Mian, A. \& Sufi, A. (2021), 'Low interest rates, market power, and productivity growth', Econometrica forthcoming.

Maksimovic, V. (1988), 'Capital structure in repeated oligopolies', Rand Journal of Economics 19(3), 389-407.

Midrigan, V. \& Xu, D. (2014), 'Finance and misallocation: Evidence from plant-level data', American Economic Review 104(2), 422-458.

Rogerson, W. (1985), 'The first-order approach to principal-agent problems', Econometrica 53(6), 1357-1367.

Telser, L. (1966), 'Cutthroat competition and the long purse', Journal of Law and Economics 9, 259-277. 
Wang, Y., Whited, T., Wu, Y. \& Xiao, K. (2021), 'Bank market power and monetary policy transmission: Evidence from a structural estimation', Journal of Finance forthcoming. 